\title{
Plumbing vs Nudging: The Lasting Effect of Efficiency Improvements on Water Conservation
}

Sumit Agarwal ( $\square$ ushakri@yahoo.com )

National University of Singapore https://orcid.org/0000-0002-8305-3786

\section{Eduardo Araral}

National University of Singapore

\section{Mingxuan Fan}

NUS

Qin $\mathrm{Yu}$

NUS

Huanhuan Zheng

NUS

\section{Article}

Keywords: water conservation, improving plumbing, nudging consumers

Posted Date: March 19th, 2021

DOI: https://doi.org/10.21203/rs.3.rs-244481/v1

License: (c) (1) This work is licensed under a Creative Commons Attribution 4.0 International License. Read Full License

Version of Record: A version of this preprint was published at Nature Human Behaviour on March 31st, 2022. See the published version at https://doi.org/10.1038/s41562-022-01320-y. 


\title{
Plumbing vs Nudging: The Lasting Effect of Efficiency Improvements on Water Conservation
}

\author{
Sumit Agarwal Eduardo Araral \\ bizagarw@nus.edu.sg ed_araral@nus.edu.sg \\ Mingxuan Fan* Yu Qin Huanhuan Zheng \\ sppfanm@nus.edu.sg bizqyu@nus.edu.sg sppzhen@nus.edu.sg
}

National University of Singapore

\begin{abstract}
Mega-cities worldwide are facing water security challenges. We investigate two solutions to urban water security: improving plumbing and nudging consumers. We show that improving plumbing alone generates long-lasting effects in water conservation. Using anonymised water consumption data based on water bills from 1.5 million accounts in Singapore over 10 years, our staggered difference-indifferences estimates show that a nation-wide Home Improvement Programme reduces residential water consumption by $3.5 \%$. The effect persists for a decade and is observed across population subgroups. The efficiency improvements also help in mitigating the effect of extreme environmental conditions on water use. Nation-wide nudging through peer comparison may not achieve similar outcomes.
\end{abstract}


Mega-cities worldwide are facing water security challenges due to rapid population growth and declining supply and quality of water resources. Governments have responded by developing more infrastructure to increase supply and managing demand through increasing tariffs, improving efficiency, and nudging water conservation. In this paper, we study the effect of efficiency improvements through plumbing (i.e. installing water efficient fittings), in comparison to behavioural nudging through peer comparison, using 98.2 million observations of monthly water consumption from 1.5 million households over ten years in Singapore.

Studies, mostly randomized control trials, have shown that nudging consumers via peer comparison to conserve water and energy is only effective in the short-run. ${ }^{1,2}$ In the medium term (two to four years), the effect tends to decay or disappear. ${ }^{3,4,5}$ Evidence on the effectiveness of other behavioural interventions, such as information labels, commitment devices, real-time feedback, and goal setting, etc., is mixed ${ }^{6}$. Relatively little attention has been paid to the scale-up of these behavioural interventions, the effectiveness of which may be affected by many factors, such as type of information ${ }^{7}$, delivery mode ${ }^{6}$, frequency of information provision ${ }^{8,9,10}$, target group $^{11}$, and welfare implications ${ }^{12}$.

There has been a dearth of credible evidence on the effectiveness and cost-effectiveness of efficiency subsidy and standards ${ }^{13,14}$. Studies ${ }^{15,16,17,18}$ on energy efficiency retrofit find that the electricity savings through residential weatherization or appliance replacement are small and the rebound effects may outweigh the efficiency improvements resulting in increased energy consumption $^{19}$. Other studies ${ }^{20,21,22,23}$ find energy standards, especially building codes, effective in reducing energy consumption. However, the long-term effect may vary by energy sources ${ }^{24}$. 
In this study, we focus on evaluating the effect of water efficiency improvements, leveraging on the nation-wide Home Improvement Programme (HIP) in Singapore, which provides heavily subsidized optional replacement of sanitary fittings such as water closet and water taps. We use anonymized monthly water billing data for all public housing households or 1.5 million accounts from 2011 to 2019, combined with housing characteristics, block-level demographics, and weather and environmental controls. Our estimates from a staggered difference-in-differences approach show that the efficiency improvements through HIP results in a 3.5\% reduction in residential water use. This effect is persistent across population subgroups and lasts at least a decade after project completion. As climate and environmental changes pose increasing uncertainty on water supply and usage, we show that efficiency improvements may help mitigate such uncertainty in water use under extreme weather and pollution conditions.

We also investigate a nation-wide utility bill update, which incorporates information such as neighbourhood average water consumption, that nudges water conservation through peer comparison. We are unable to attribute any clear reduction in water consumption to this intervention.

Our main contribution to the literature is to show for the first time that (1) improving water efficiency through plumbing provides long-lasting effects in water conservation; (2) efficiency improvements could mitigate the effect of extreme weather conditions on water use; and (3) nationwide nudging through peer comparison may not achieve similar outcomes. 


\section{Effect of efficiency improvements through plumbing}

\section{Home Improvement Programme (HIP)}

In Singapore, over $80 \%$ of the population lives in public housing developed and managed by the Housing and Development Board (HDB), out of which about $90 \%$ of the residents own their home. Currently, there are more than one million HDB flats, some of them built in as early as the 1960s.

The Home Improvement Programme (HIP) is an upgrading programme, introduced in 2007, to resolve common maintenance problems of ageing HDB flats. It first targeted flats built before 1986 and later expanded to flats built before 1997. Residents collectively decide whether the block will undergo upgrading. Among the blocks offered HIP, 99.6\% voted for it to be implemented.

Data on HIP polling results, project status, timing of announcement, and billing were collected from HDB Map Services. Based on the data we collected, 55\% of all HDB blocks were eligible for HIP, out of which 56\% had been or were being upgraded, as of December 2019. Information on the exact timing for the commencement and completion of upgrading work is not available. According to the official guide on HIP, upgrading work typically takes 18 months to complete after the announcement of a successful poll, with about 10 working days of upgrading work per flat. Using this cut-off, 2,262 blocks of close to 360,000 flats have completed the upgrade by December 2019. Supplementary Figure B.1 and Figure B.2 provides details the distribution of HIP flats by location and over time.

The programme includes essential improvements that are necessary for public health and safety, the cost for which are fully covered by the government. It also includes several optional improvements, such as improvements of all existing bathrooms, which has implications on water usage as the new fittings are required to meet minimal water efficiency standards in place at the 
time of upgrading and are likely more efficient than the old installations. The optional improvements are heavily subsidized with households paying between $5 \%$ to $12.5 \%$ of the total cost based upon the flat type (see Supplementary Table B.1). On average, the take-up rate for this optional upgrade is $70 \%$ according to the HDB.

\section{Average intent-to-treat effect}

As shown in Figure 1, the mean monthly water consumption for both HIP and non-HIP flats reduced over time. We observe that the trend for the pre-HIP flats followed closely to that of the non-HIP flats while the post-HIP water consumption was lower throughout the sample period.

To empirically evaluate the average effect of efficiency improvements on water consumption, we use a staggered difference-in-differences regression approach comparing the monthly water consumption for HIP flats before (pre-HIP) and after (post-HIP) project completion, relative to non-HIP flats. In our empirical estimation, we take into account time-invariant household characteristics, seasonality, spatial variations in weather and pollution, economy-wide common shocks as well as group specific pre-trend for HIP and non-HIP flats.

Table 1 column (4) shows the baseline estimate for the average effect of efficiency improvements on residential water consumption (by estimating equation (1) in Methods). Upon the completion of HIP, the treated accounts reduced water consumption by $3.5 \%$. Evaluated at the mean monthly water consumption of $17.24 \mathrm{~m}^{3}$ for HIP flats before project completion, $0.6 \mathrm{~m}^{3}$ of water was saved per household per month. With approximately 360,000 flats completing the upgrade, annual total water consumption was estimated to decline by $2,592,000 \mathrm{~m}^{3}$ by December 2019. Note that not all flats in the treatment group went through the optional bathroom upgrade. As we do not have 
information for the treatment status for each individual flat, this estimate should be considered as an average intent-to-treat effect.

For robustness checks, we consider (1) alternative cut-off for project completion: instead of using 18 months after polling, we use billing date as the proxy for project completion; (2) alternative samples: we consider various sample restrictions, including restricting the control groups to flats of similar age as HIP flats and limit the sample to HIP flats only; (3) alternative clustering for standard errors. The changes in effect size across models are small, if any (see Supplementary A).

\section{Dynamic effect}

In addition to the average treatment effect, we study the long-term and evolutionary effects of efficiency improvements by conducting an event study (equation (2) in Methods). The coefficients of this estimation compare the water consumption of HIP flats in each 12-month period before and after project completion to that of the non-HIP flats.

Figure 2 presents the coefficients with the corresponding $95 \%$ confidence intervals where $\mathrm{T} 0$ is the month of project completion taking 18 months after the announcement of HIP polling results as the cut-off, while $\mathrm{T}-1$ and $\mathrm{T}+1$ refer to the 12 months pre- and post-project completion respectively. In all time periods before HIP, there was no statistically significant difference in the mean water consumption for the treatment and control groups, which validates the difference-indifferences research design. Upon the completion of HIP, there is an immediate reduction in water consumption for the treatment group. The effect is persistent throughout the sample period, which covers up to 10 years after HIP completion. Supplementary Figure B.4 presents similar analysis using alternative samples and the long-term effects are consistent across samples. 


\section{Heterogeneous effect}

We next study the heterogeneous effect of efficiency improvements on population subgroups with varied housing characteristics, water demand and block-level demographics (equation (3) in Methods). We compare the monthly water consumption for each subgroup of HIP flats before and after project completion, relative to their counterparts among the non-HIP flats.

Firstly, we investigate the effect of efficiency improvements by housing characteristics such as flat type and age. As flat types are reflective of income levels, we may observe heterogeneous effect of HIP on water consumption if the take-up rate for optional upgrades differs across income groups. Figure 3(a) shows that HIP has a significant effect in reducing water consumption across all flat types with the effect size for HDB 1-/2-rooms (2.0\%) and HDB 5-room/executive flats (3.0\%) smaller than the HDB 3-room (3.5\%) and 4-room (3.6\%) flats.

Similarly, if the water efficiency of existing fittings in flats built over time improves, we would observe a decreasing effect of HIP on water consumption. We divide the sample into five timewindows: before 1980, 1980-1983, 1984-1986, 1987-1997 and after 1997. Flats in the first three windows qualify for the first phase of HIP and account for $99 \%$ of all HIP flats with similar number of HIP flats in each window. Flats in the fourth window qualify for the second phase of HIP while the fifth window contains no HIP flats. Figure 3(b) shows, as expected, that the effect of HIP on residential water consumption to reduce from $3.8 \%$ for flats built before 1980 , to $3.6 \%$ for flats built between 1980 and 1983 and to $3.1 \%$ for flats built between 1984 and 1986 .

Next, we divide the sample into water consumption quartiles by the mean water usage for each account as baseline water demand determines the upper limit of reduction in water consumption through efficiency improvements. Figure 3(c) shows that, consistent with our hypothesis, HIP 
significantly reduces water consumption across all subgroups and the magnitude of reduction increases from $1.6 \%$ for the first quartile, to $3.1 \%, 3.9 \%$ and $4.9 \%$ for second, third and fourth quartile respectively. The trend of increasing effect size as water consumption increases also holds across subgroups with varied housing characteristics.

Lastly, we evaluate the heterogeneous effect of HIP by block-level demographic characteristics such as family size, gender, ethnicity and age. As the improvement in water efficiency is not an intended outcome of the project, we are not expecting immediate behavioural changes that may differ by demographic characteristics. If HIP does have heterogeneous effects across demographic groups, it is likely linked to varied baseline water demand. We divide HDB blocks into quartiles based on their 2011 mean family size, percentage of males, percentage of Chinese, percentage of elderly, and percentage of young adults. Figure 3(d) to (h) show that the effects of HIP are similar across subgroups with varied block-level demographic characteristics with few exceptions. For example, the effect on the lowest quartile of family size is smaller $(2.7 \%)$. This is consistent with our previous results as smaller households are likely to have lower water consumption and less room for reduction.

Supplementary Figure B.5-10 present more details on the subgroup samples and the evolutionary effects of efficiency improvements by subgroup.

\section{Interaction of HIP and extreme environmental conditions}

In our baseline model, we find that a $1 \%$ increase in monthly mean temperature (equivalent to 0.28 ${ }^{\circ} \mathrm{C}$, evaluated at the mean) is associated with a $0.48 \%$ increase in water consumption for an average household. We observe no significant effect of $1 \%$ change in the number of rainy days, and PSI on water consumption. The small effect of a $1 \%$ change in weather and pollution on water 
consumption is expected because of the limited variation in temperature, rainfall, and air pollution in Singapore. We therefore focus on how efficiency improvements modify the effect of the extreme changes in environmental conditions by interacting the indicator variables for extreme temperature, rainfall and air pollution with the HIP status variables (equation (4) in Methods).

We find that when it is extremely hot (monthly mean temperature above $28.9{ }^{\circ} \mathrm{C}$ ), the monthly water consumption for an average non-HIP flat increases by $0.7 \%$. The effect on pre-HIP flats is similar. However, upon project completion, excessive heat no longer has significant effect on residential water consumption for HIP flats, as illustrated in Figure 4(a).

We also find that excessive rain (more than 22 rainy days in a month) does not affect water consumption for non-HIP flat; however, it reduces water consumption by $1 \%$ for an average preHIP flat. Upon HIP completion, the effect size of excessive number of rainy days reduces and is no longer statistically significant, as shown in Figure 4(b).

Lastly, when air quality is unhealthy with PSI above 100, the non-HIP and pre-HIP flats are affected in similar ways with an increase in water consumption by $0.5 \%$ and $0.7 \%$ respectively. The completion of HIP makes residential water consumption less susceptible to air pollution with its effect significantly reduced by $1.1 \%$ and no longer statistically significant as shown in Figure 4(c).

The findings in this section suggest that in addition to directly reducing water consumption, efficiency improvements may also mitigate the effect of extreme weather and air pollution. Results using alternative model specifications are shown in Supplementary Table B.3 and long-term effects of the interaction between efficiency improvements and extreme environmental conditions are presented in Supplementary Figure B.11. 


\section{Nation-wide nudging through peer comparison}

In the above sections, we show that efficiency improvements through plumbing reduces water consumption and the effect is persistent up to at least ten years. To put this in perspective, we evaluate another nation-wide initiative that specifically targets residential water conservation.

In August 2016, the utility bill for residential consumers were redesigned in Singapore. The new layout of the utility bill allows consumers to view their current and past five months water consumption. The consumers are also able to compare their own water usage with the average consumption of their neighbours living in the same flat type within the same block. Additionally, national average water consumption is provided along with tips on water conservation.

As the bill update was implemented nation-wide, we do not have a suitable control group to clearly identify the causal effect of peer comparison on residential water consumption. However, for the peer comparison to work, we would likely observe (1) the mean water consumption for the comparison groups or block-flat-type groups to reduce; (2) the within block-flat-type group standard deviation to reduce; (3) more reduction for the accounts that consumes more than the group mean or the benchmark provided in the newly designed bill. We do not observe any of the above-mentioned trends through our graphical inspection (as shown in Supplementary Figure B.12.).

Table 2 shows the empirical estimates on the effect of peer comparison. We restrict the sample period to November 2016 as a series of other water conservation initiatives were implemented from December 2016, such as a massive media campaign in December 2016 due to a severe drought affecting resource availability, and the announcement and implementation of water tariff increase in February and July 2017. 
In columns (1) and (2), we compare the group mean and within group standard deviation in water consumption before and after the information for peer comparison was made available through utility bills (equation (5) in Methods). We do not observe any statistically significant reduction in both outcome variables. In column (3), we compare the water consumption for the accounts that consumes above the benchmark, or the mean water consumption for the same type of flats within the same block, before and after the intervention, relative to those who consume below the benchmark (equation (6) in Methods). We find no statistically different reduction in water consumption for the two groups.

We investigate the evolutionary effect of peer comparison on all three outcome variables to address the concern that households may not react immediately to the bill update (equation (7) and (8) in Methods). We find no trend in the coefficients over time that signals the peer comparison taking effect slowly (see Supplementary Figure B.13), though we acknowledge the limitation of a short response period being suitable for evaluation. We also look into the heterogeneous effect of peer comparison by subgroups of population (equation (9) and (10) in Methods), by flat type, flat age, and water consumption quartiles, and we are unable to identify any effects across all subgroups (see Supplementary Figure B.14).

Overall, we are unable to attribute any clear reduction in water consumption to the nation-wide nudging through redesigned utility bill. Even though the literature has shown a promising local treatment effect of peer comparison in conservation both globally and in Singapore ${ }^{25}$, the scale-up of such interventions may not work based on our results. 


\section{Conclusion}

In this paper, we show that improving plumbing could obtain long-lasting effects in water conservation. Using monthly billing data from 1.5 million accounts in Singapore over 10 years, we show that a nation-wide Home Improvement Programme reduces residential water consumption by $3.5 \%$ on average. Evaluated at the mean before HIP, the program reduces monthly water consumption by 0.6 cubic meters per household on average. Although the savings on water tariff alone are not able to recover the upfront cost at the household level, we should note that efficiency improvements is not the main focus of the program, yet it provides additional benefits to the upgrade and results in larger water savings than a national-wide behavioural nudging. As Singapore aims to reduce residential water consumption from 141 litres per person per day in 2018 to 130 litres in 2030, our back-of-the-envelope estimation show that the $3.5 \%$ water savings could potentially contribute to half of this conservation target for the HIP households.

We find that the effect of efficiency improvements on water consumption last at least a decade, in contrary to the short-term effect of behavioural nudging. In terms of policy design, efficiency improvements is more straightforward, unlike behavioural interventions that require careful calibrations to ensure effectiveness. We also show that the effect of efficiency improvements is observed across population subgroups. It helps in mitigating the effect of extreme environmental conditions on water use. Nation-wide nudging through peer comparison, however, may not achieve similar outcomes.

There are a few caveats in our findings on the effectiveness of efficiency improvements. Firstly, we are unable to control for time-varying household characteristics due to lack of data. It is possible that time-variant changes in household characteristics may affect the accuracy of our 
estimates. However, it is unlikely that the average changes in household characteristics for the treatment group would differ from that of the control group given the exogenous selection into the program and the fact that our data covers $80 \%$ of the total population in the country. Secondly, we do not have information on the specifications of water fittings before or after HIP. The efficiency improvements and the estimated effect are based on technological advances in the water fittings over time. Thirdly, apart for the overall take-up rate of $70 \%$, we do not have information on the exact households that opted in vs out of the optional bathroom upgrade, therefore we are only able to estimate the intent-to-treat effect of the efficiency improvements.

This paper contributes to the literature by showing for the first-time robust empirical evidence that (1) improving plumbing can obtain long-lasting effects on water conservation; (2) efficiency improvements helps in mitigating the effect of extreme weather and environmental conditions on water use; and (3) nation-wide nudging through peer comparison may not achieve similar outcomes.

\section{Methods}

\section{Data}

Water consumption: We use water consumption data obtained from PUB, Singapore's national water agency. It contains monthly water consumption based on water bills for all HDB flats with 1,506,296 unique anonymized accounts from January 2011 to December 2019. The data includes anonymized account number that changes every time a household moves, block identifier/postal code, and flat type classified by the number of rooms.

Block-level housing characteristics and demographics: Housing characteristics such as year of completion were collected through publicly available database provided by the Government of 
Singapore. Additionally, we have access to administrative data on the demographics and residential addresses for 2.8 million adult Singaporeans in 2011. Although we are unable to match these individuals to account level water consumption due to the anonymization of premise identifier in the water consumption data, we could derive block-level demographics, such as mean family size, percentage of males (vs. female), percentage of Chinese (vs. other ethnicity), percentage of elderly (born before 1950) and percentage of young adults (born after 1990).

Weather and air quality: We acquire daily weather observations by station from the Meteorological Service Singapore and historical 24-hour Pollutant Standards Index (PSI) readings by monitor from the National Environmental Agency. We generate block-specific monthly weather and air quality indicators such as mean temperature, number of rainy days, and mean PSI using observations across all stations within 10-kilometer $(\mathrm{km})$ radius of the block using Inverse Distance Weighting method. The trend and spatial variations over time are shown in Supplementary Figure B.3.

Sample: In our baseline analysis, we include sample from January 2011 to December 2019. We exclude extreme values of the top and bottom $1 \%$ observations in water consumption for each flat type to account for potential measurement errors caused by water leakage, bill adjustment, and problematic meter readings. We exclude accounts with missing information on HIP status. The resulting baseline sample consists of 98,291,320 observations from 1,503,350 accounts in 10,188 HDB blocks.

Sample statistics are shown in Supplementary Table B.2. The mean monthly water consumption is $17.24 \mathrm{~m}^{3}$ for HIP flats before project completion, higher than $16.8 \mathrm{~m}^{3}$ for non-HIP flats; while the post-project mean for HIP flats is reduced to $15.42 \mathrm{~m}^{3}$. 
The treatment and control groups comprise a different mix of flats in terms of year of construction and flat type. This is expected as only older flats built before 1997 were eligible for HIP and the composition of flat types evolved over time to accommodate the changing demographics. Similarly, we observe differences in demographic composition between HIP and non-HIP flats. During the sample period, the differences in weather and air quality between treatment and control groups were small.

\section{Empirical method}

\section{Effect of efficiency improvements}

We analyse the effect of efficiency improvements on residential water consumption using a staggered difference-in-differences regression approach. The treatment group is the HDB flats that completed HIP before December 2019, and the control group is the HDB flats that did not implement or complete the project. We use sample from January 2011 to December 2019 therefore the pre-treatment time-periods range from 1 to 107 months while the post-treatment periods range from 1 to 124 months due to the staggered implementation of HIP.

To evaluate the average effect of efficiency improvements on water consumption, we first estimate the following equation:

$$
\ln W_{i j t}=\delta \text { Post }_{t} \times \text { Treat }_{i}+\boldsymbol{X}_{j t} \boldsymbol{\beta}+\theta_{k} \tau+\alpha_{i}+\gamma_{t}+\epsilon_{i j t}
$$

The dependent variable is the natural logarithm of monthly water consumption for household $i$ living in block $j$ in time period $t$. Post $t_{t}$ is an indicator variable that takes the value of 1 for time periods post the completion of HIP. Treat ${ }_{i}$ is an indicator variable for the treatment group, that is, household that completed HIP. $X_{j t}$ is a vector of weather and air quality controls such as the log of 
mean temperature, number of rainy days, and mean PSI, which vary by block and time. We allow the control and treatment groups to have different water consumption trends by including groupspecific linear time trend $\tau$. We include household fixed effects $\alpha_{i}$ to account for time-invariant household characteristics and time fixed effect $\gamma_{t}$ to account for seasonality and other economywide common shocks. The coefficient of interest $\delta$ measures the average post-completion monthly water consumption for the treatment group relative to the control group. Standard errors in the baseline estimation are two-way clustered by block and year-month.

We further explore the dynamics of water consumption change due to efficiency improvements through an event study analysis and estimate the following model:

$$
\ln W_{i j t}=\sum_{l=-9}^{10} \delta_{l} D_{i t}^{\text {year }} \times \text { Treat }_{i}+\boldsymbol{X}_{j t} \boldsymbol{\beta}+\theta_{k} \tau+\alpha_{i}+\gamma_{t}+\epsilon_{i j t}
$$

where we interact the treatment indicator with a set of relative time dummies $D_{i t}{ }^{\text {year }}$ that correspond to each 12-month lead and lag of the treatment timing. In our sample, the data covers observations up to 9 years before and 10 years after the HIP implementation. The coefficients of interest $\delta l$ measure the average difference in water consumption between the control and treatment group in each 12-month period. In addition, this setting also allows us to explicitly test the parallel trend assumption of the difference-in-differences design.

We study the heterogeneous effect of efficiency improvements on subgroups of population by housing characteristics (i.e. by flat type, flat age categories), water demand (i.e. water consumption quartile), and block-level demographic characteristics (i.e. quartile of family size, percentage of 
males, percentage of Chinese, percentage of elderly and percentage of young family), using the following specification:

$$
\ln W_{i j t}=\sum_{n=1}^{N} \delta_{n} G_{i} \times \text { Post }_{t} \times \text { Treat }_{i}+\boldsymbol{X}_{j t} \boldsymbol{\beta}+\theta_{k} \tau+\alpha_{i}+\gamma_{t}+\epsilon_{i j t}
$$

where $N$ is the number of subgroups and $G_{i}$ is the subgroup indicator. The coefficients $\delta_{1}$ to $\delta_{N}$ measure the heterogeneous effect of efficiency improvements.

We are particularly interested in whether efficiency improvements modify the effect of environmental conditions. To this end, we estimate the interaction effect between weather/air quality variables and HIP through the following equation:

$$
\ln W_{i j t}=\text { STreat }_{i} \times \text { Post }_{t}+\beta_{1} X_{j t}+\beta_{2} X_{j t} \times \text { Treat }_{i}+\beta_{3} \text { Treat }_{i} \times \text { Post }_{t}+\boldsymbol{X}_{j t} \boldsymbol{\beta}+\theta_{k} \tau+\alpha_{i}+\gamma_{t}+\epsilon_{i j t}
$$

where $X_{j t}$ is a weather or pollution control variable for all households in block $j$ during time $t$. The coefficients $\beta_{1}, \beta_{1}+\beta_{2}$ and $\beta_{1}+\beta_{2}+\beta_{3}$ represent the effect of weather and pollution on non-HIP flats, HIP flats before and after project completion, respectively.

\section{Effect of peer comparison}

Firstly, we expect peer comparison to reduce both the mean water consumption and within blockflat-type standard deviation. To test this, we estimate the following equation:

$$
\ln Y_{j t}=\delta \text { Post }_{t}+\boldsymbol{X}_{j t} \boldsymbol{\beta}+\alpha_{j}+\gamma_{t}^{\text {Year }}+\theta_{t}^{\text {Month }}+\epsilon_{j t}
$$


Where $Y_{j t}$ is the mean or standard deviation of water consumption for block-flat-type $j$ in month $t$; Post $t_{t}$ is and indicator variable that takes the value of 1 for time periods after the bill update; $X_{j t}$ is a vector of weather and air quality controls such as the log of mean temperature, number of rainy days, and mean PSI, which vary by block and time. We include group fixed effects $\alpha_{j}$ to account for time-invariant group characteristics; month fixed effects $\theta_{t}^{\text {Month }}$ to account for seasonality; and year fixed effects $\gamma_{t}^{\text {Year }}$ to account for common economy-wide shocks each year.

Secondly, for the peer comparison to work, we would expect more reduction for the accounts that consume more than the group mean or the benchmark provided in the newly designed bill. We divide the accounts into two groups based upon pre-treatment mean water consumption. We compare water consumption before and after bill update for the above-the-mean group, relative to that of the blow-the-mean group by estimating the following equation:

$$
\ln W_{i t}=\delta \text { Post }_{t} \times \text { Above }_{i}+\boldsymbol{X}_{i t} \boldsymbol{\beta}+\alpha_{i}+r_{t}+\epsilon_{i t}
$$

Where $W_{i t}$ is the water consumption for account $i$ in time period $t$; Above $i$ is an indicator variable for the above-the-mean group; $\alpha$ and $\gamma$ are account fixed effects and year-month fixed effects respectively.

We estimate the evolutionary and heterogeneous effect of peer comparison for the three outcome variables of concern through the following equations:

$$
\begin{gathered}
\ln Y_{j t}=\sum_{n=1}^{4} \delta_{n} D_{t}+\boldsymbol{X}_{j t} \boldsymbol{\beta}+\alpha_{i}+\gamma_{t}^{\text {Year }}+\theta_{t}^{\text {Month }}+\epsilon_{j t} \\
\ln W_{i t}=\sum_{n=1}^{4} \delta_{n} D_{t} \times \text { Above }_{i}+\boldsymbol{X}_{j t} \boldsymbol{\beta}+\alpha_{i}+\gamma_{t}+\epsilon_{j t}
\end{gathered}
$$




$$
\begin{gathered}
\ln Y_{j t}=\sum_{n=1}^{N} \delta_{n} G_{j} \times \text { Post }_{t}+\boldsymbol{X}_{j t} \boldsymbol{\beta}+\alpha_{i}+\gamma_{t}^{\text {Year }}+\theta_{t}^{\text {Month }}+\epsilon_{j t} \\
\ln W_{i t}=\sum_{n=1}^{N} \delta_{n} G_{i} \times \text { Post }_{t} \times \text { Above }_{i}+\boldsymbol{X}_{j t} \boldsymbol{\beta}+\alpha_{i}+\gamma_{t}+\epsilon_{j t}
\end{gathered}
$$

where $D$ is the time dummies for each of the post bill update month and $G$ is sub-groups dummies.

\section{Data availability statement}

The data for this study is provided PUB, Singapore's National Water Agency under nondisclosure agreement for the current study and is not publicly available. However, it may be obtained with data use agreement with the PUB.

\section{Code availability statement}

Stata code for data cleaning and analysis will be made available upon request. 


\section{References}

1. Hunt Allcott. Social norms and energy conservation. Journal of Public Economics, 95(910):1082-1095, oct 2011.

2. Daniel A. Brent, Joseph H. Cook, and Skylar Olsen. Social comparisons, household water use, and participation in utility conservation programs: Evidence from three randomized trials. Journal of the Association of Environmental and Resource Economists, 2(4):597-627, dec 2015.

3. Paul J Ferraro, Juan Jose Miranda, and Michael K Price. The persistence of treatment effects with norm-based policy instruments: Evidence from a randomized environmental policy experiment. American Economic Review, 101(3):318-322, may 2011.

4. Paul J. Ferraro and Michael K. Price. Using nonpecuniary strategies to influence behavior: Evidence from a large-scale field experiment. Review of Economics and Statistics, 95(1):6473, mar 2013.

5. Hunt Allcott and Todd Rogers. The short-run and long-run effects of behavioral interventions: Experimental evidence from energy conservation. American Economic Review, 104(10):30033037, oct 2014.

6. Mark A. Andor and Katja M. Fels. Behavioral economics and energy conservation - a systematic review of non-price interventions and their causal effects. Ecological Economics, 148:178-210, jun 2018.

7. Richard G. Newell and Juha Siikamäki. Nudging energy efficiency behavior: The role of information labels. Journal of the Association of Environmental and Resource Economists, 1(4):555-598, dec 2014.

8. Ben Gilbert and Joshua Graff Zivin. Dynamic salience with intermittent billing: Evidence from smart electricity meters. Journal of Economic Behavior \& Organization, 107:176-190, nov 2014.

9. Katrina Jessoe and David Rapson. Knowledge is (less) power: Experimental evidence from residential energy use. American Economic Review, 104(4):1417-1438, apr 2014.

10. Casey J. Wichman. Information provision and consumer behavior: A natural experiment in billing frequency. Journal of Public Economics, 152:13-33, aug 2017.

11. Dora L. Costa and Matthew E. Kahn. Energy conservation "nudges" and environmentalist ideology: Evidence from a randomized residential electricity field experiment. Journal of the European Economic Association, 11(3):680-702, jun 2013.

12. Hunt Allcott and Judd B. Kessler. The welfare effects of nudges: A case study of energy use social comparisons. American Economic Journal: Applied Economics, 11(1):236- 276, jan 2019.

13. Hunt Allcott and Michael Greenstone. Is there an energy efficiency gap? Journal of Economic Perspectives, 26(1):3-28, feb 2012. 
14. Kenneth Gillingham, Amelia Keyes, and Karen Palmer. Advances in evaluating energy efficiency policies and programs. Annual Review of Resource Economics, 10(1):511-532, oct 2018.

15. Joshua Graff Zivin and Kevin Novan. Upgrading efficiency and behavior: Electricity savings from residential weatherization programs. The Energy Journal, 37(4), 2016.

16. Hunt Allcott and Michael Greenstone. Measuring the welfare effects of residential energy efficiency programs. Technical report, NBER Working Papers 23386., 2017.

17. Meredith Fowlie, Michael Greenstone, and Catherine Wolfram. Do energy efficiency investments deliver? evidence from the weatherization assistance program. The Quarterly Journal of Economics, 133(3):1597-1644, jan 2018.

18. Jing Liang, Yueming Qiu, Timothy James, Benjamin L. Ruddell, Michael Dalrymple, Stevan Earl, and Alex Castelazo. Do energy retrofits work? evidence from commercial and residential buildings in phoenix. Journal of Environmental Economics and Management, 92:726-743, nov 2018.

19. Lucas W. Davis, Alan Fuchs, and Paul Gertler. Cash for coolers: Evaluating a largescale appliance replacement program in Mexico. American Economic Journal: Economic Policy, 6(4):207-238, nov 2014.

20. Grant D. Jacobsen and Matthew J. Kotchen. Are building codes effective at saving energy? evidence from residential billing data in Florida. The Review of Economics and Statistics, 95(1):34-49, March 2013.

21. Arik Levinson. How much energy do building energy codes save? evidence from California houses. American Economic Review, 106(10):2867-2894, oct 2016.

22. Yueming Qiu and Matthew E. Kahn. Better sustainability assessment of green buildings with high-frequency data. Nature Sustainability, 1(11):642-649, nov 2018.

23. Kevin Novan, Aaron Smith, and Tianxia Zhou. Residential building codes do save energy: Evidence from hourly smart-meter data. The Review of Economics and Statistics, pages 1-45, sep 2020.

24. Matthew J. Kotchen. Longer-run evidence on whether building energy codes reduce residential energy consumption. Journal of the Association of Environmental and Resource Economists, 4(1):135-153, mar 2017.

25. Sumit Agarwal, Satyanarain Rengarajan, Tien Foo Sing, and Yang Yang. Nudges from school children and electricity conservation: Evidence from the "project carbon zero" campaign in Singapore. Energy Economics, 61:29-41, jan 2017. 


\section{Acknowledgements}

All the authors acknowledge the funding and water consumption data support from the PUB, Singapore's National Water Agency.

\section{Contribution}

All authors contributed to the research design, implementation, data analysis and writing.

\section{Conflicts of interests}

None of the authors have any conflicts of interests. 


\section{Figures and Tables}

Figure 1: Trend of monthly water consumption

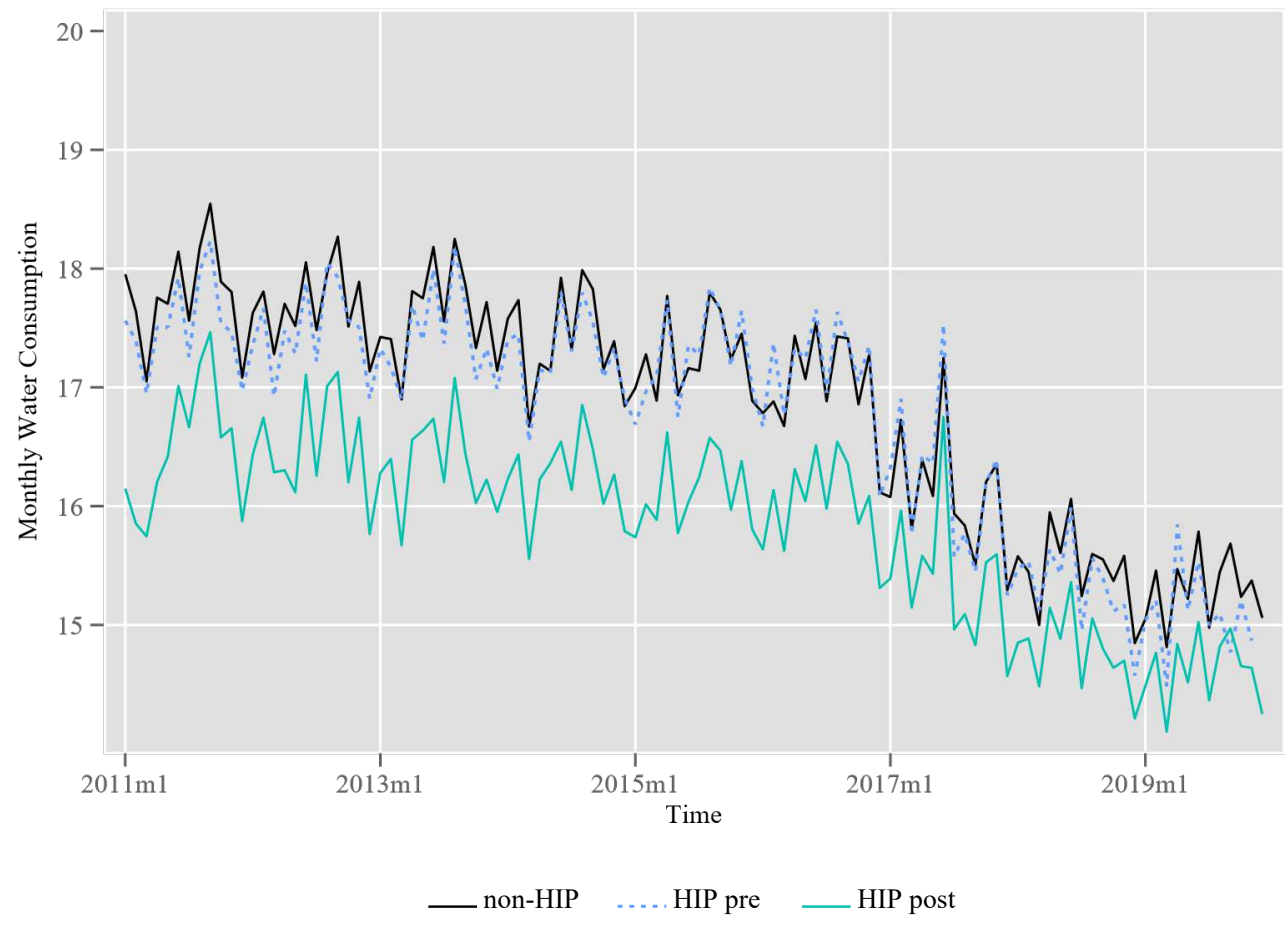

Note: The figure shows the trend in monthly mean water consumption (in cubic meter) for non-HIP flats, HIP flats before HIP completion, HIP flats after HIP completion over time. 
Figure 2: Evolutionary effect of HIP on water consumption

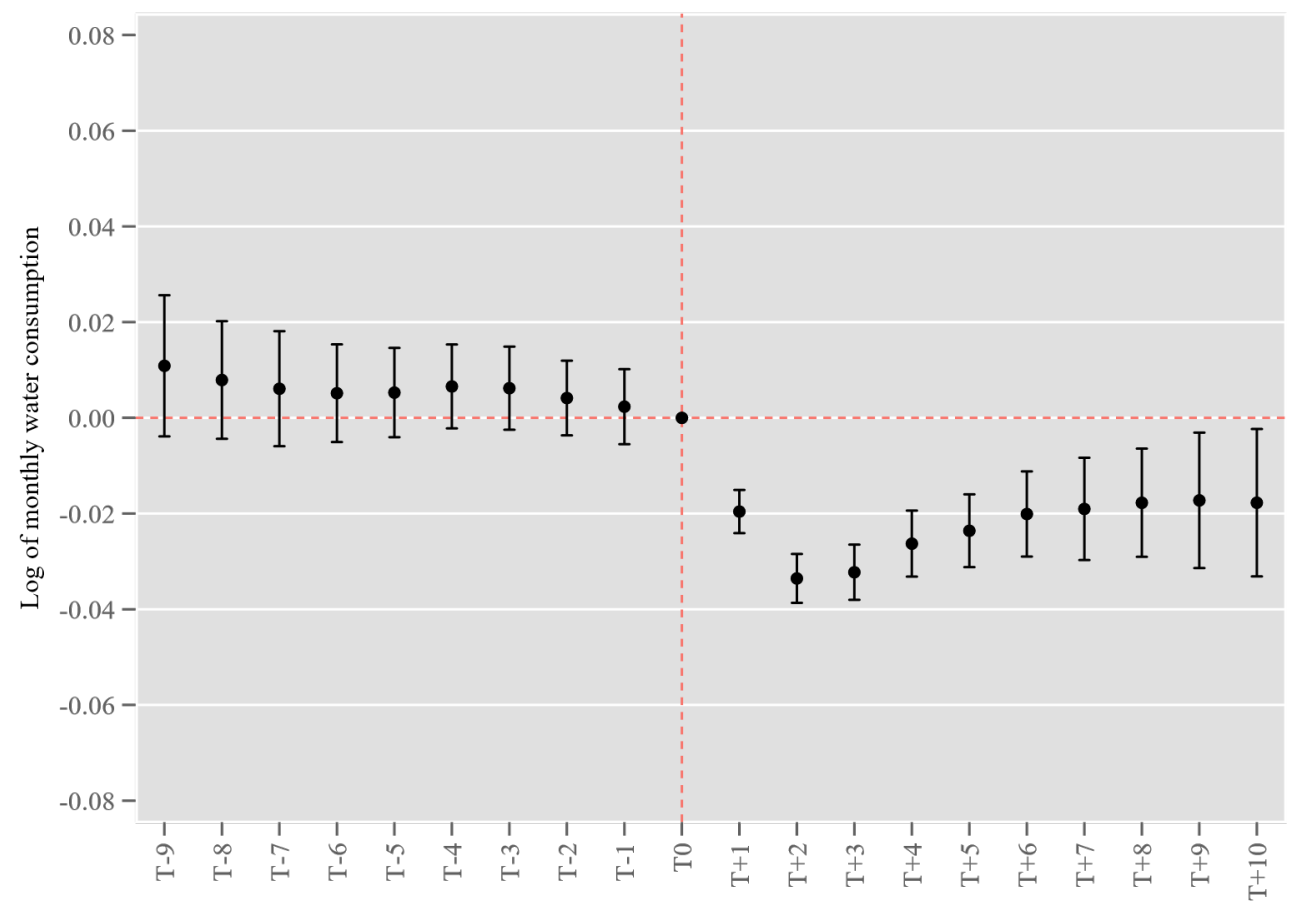

Note: The figure shows the coefficients and corresponding $95 \%$ confidence intervals for the difference in water consumption between flats that completed and did not complete HIP each year before and after HIP completion by estimating equation (3). 
Figure 3: Heterogeneous effect by housing characteristics, water demand and block-level demographics

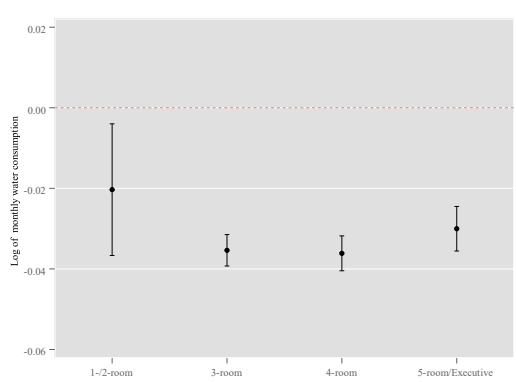

(a) By flat type

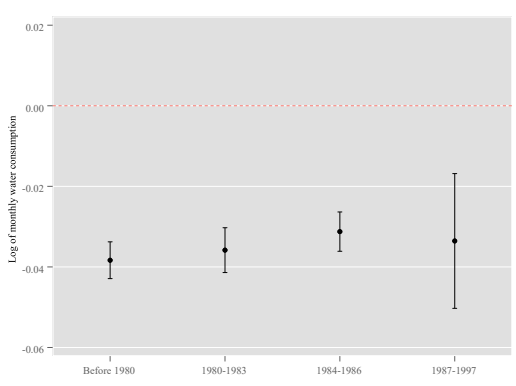

(b) By year of construction

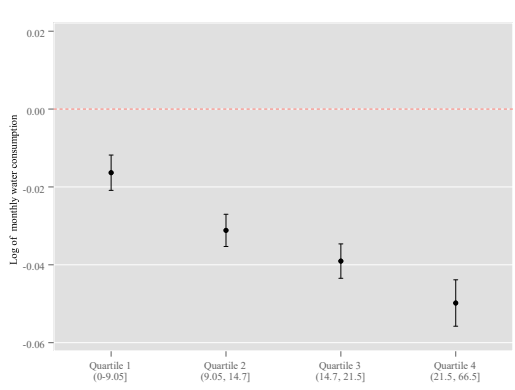

(c) By water consumption quartile

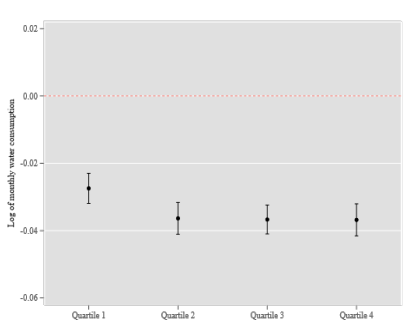

(d) By family size

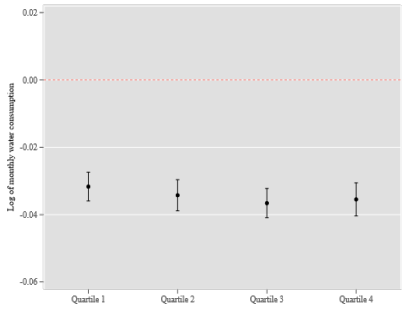

(e) By $\%$ of male

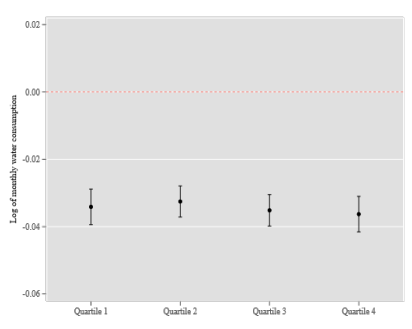

(f) By $\%$ of Chinese

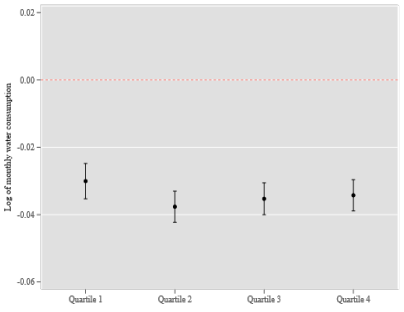

(g) By $\%$ of elderly

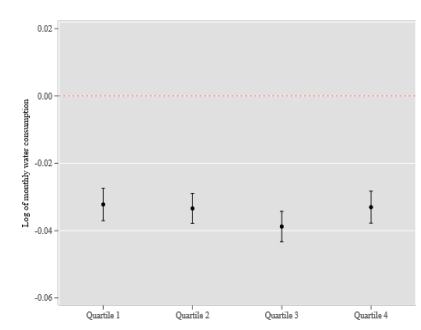

(h) By $\%$ of young family

Note: The figures show the coefficients and corresponding 95\% confidence intervals for the effect of HIP on monthly water consumption for each subgroup by estimating equation (4). Sub-figures (a), (b) and (c) show the effects by flat type, year of construction, and water consumption quartile, respectively. Sub-figures (d) to (h) present the heterogeneous effects by quartiles of family size, percentage of male, percentage of Chinese, percentage of elderly and percentage of young family. 
Figure 4: Effect of extreme environmental conditions on HIP vs non-HIP flats

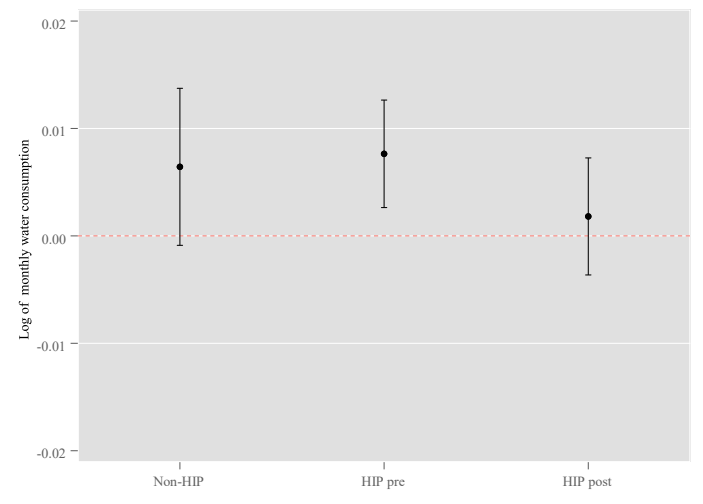

(a) Temperature

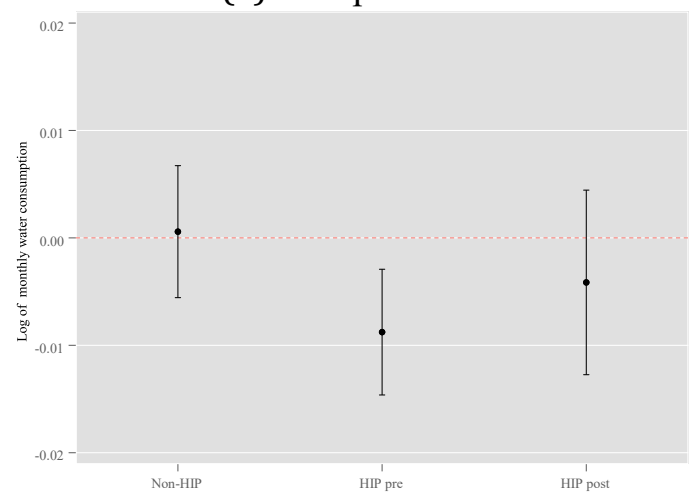

(b) Number of rainy days

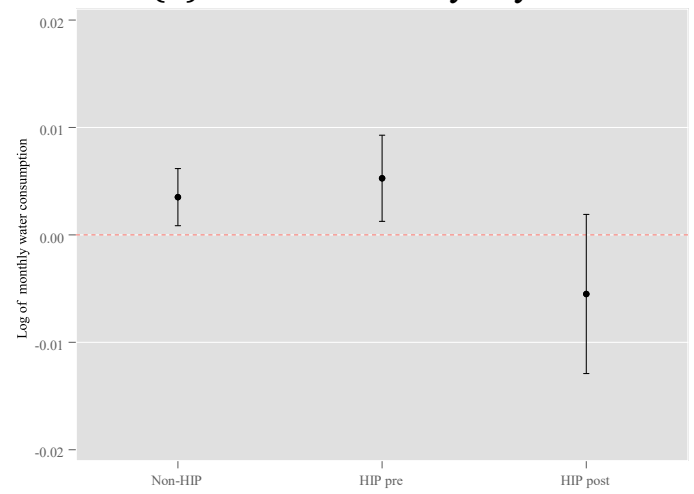

(c) PSI

Note: The figures show the coefficients and corresponding $95 \%$ confidence intervals for the effect of high temperature, excessive number of rainy days and high PSI on non-HIP flats $(\beta 1)$, HIP flats before $(\beta 1+\beta 2)$ and after $(\beta 1+\beta 2+\beta 3)$ project completion, by estimating equation (5). To be more specific, the coefficients in Panels (a), (b) and (c) correspond to Table A.2.3 column (5) row 2, row 2+5, and row $2+5+6$; column (6) row 3 , row $3+7$, and row $3+7+8$; and column (7) row 4 , row $4+9$, and row $4+9+10$, respectively. 
Table 1: Average intent-to-treat effect of HIP on water consumption
(1)
(2)
(3)
(4)

Dependent variable: Log of water consumption

\begin{tabular}{lcccc}
\hline HIP*Completed & $-0.035^{* * *}$ & $-0.035^{* * *}$ & $-0.035^{* * *}$ & $-0.035^{* * *}$ \\
Weather control & $(0.002)$ & $(0.002)$ & $(0.002)$ & $(0.002)$ \\
Pollution control & Yes & Yes & No & Yes \\
Group time trend & Yes & Yes & No & Yes \\
Account FE & Yes & Yes & Yes & Yes \\
Block FE & No & Yes & Yes & Yes \\
Year-month FE & Yes & No & No & No \\
Year FE & Yes & No & Yes & Yes \\
Month FE & No & Yes & No & No \\
N & No & Yes & No & No \\
$\mathrm{R}^{2}$ & $98,291,320$ & $98,291,320$ & $98,291,320$ & $98,291,320$ \\
\hline
\end{tabular}

Note: This table presents the average intent-to-treat effect of HIP on water consumption for the treatment group post project completion, relative to the control group. The dependent variable is log of monthly water consumption. HIP is an indicator variable that takes the value of 1 for the treatment group; Completed is an indicator variable that takes the value of 1 for time periods post project completion. Column (4) shows the baseline estimates, by estimating equation (2). Column (1) alter the baseline estimation by including block fixed effects instead of account fixed effects; column (2) includes year fixed effects and month fixed effects instead of year-month fixed effects; column (3) does not include weather and pollution controls. The standard errors shown in parentheses are clustered by block and year-month. ${ }^{*} \mathrm{p}<0.1,{ }^{* *} \mathrm{p}<0.05,{ }^{* * *} \mathrm{p}$ $<0.01$. 
Table 2: Effect of peer comparison on water consumption

(1)

(3)

\begin{tabular}{lccc} 
Dependent variable: & Log of group mean & Log of within group sd & Log of water consum. \\
\hline Post bill update & -0.005 & 0.004 & \\
& $(0.006)$ & $(0.005)$ & -0.001 \\
Post bill update*Above mean & & & $(0.010)$ \\
& & Yes & Yes \\
Control & Yes & No & Yes \\
Account FE & No & Yes & No \\
Block by flat-type FE & Yes & No & Yes \\
Year-month FE & No & Yes & No \\
Year FE & Yes & Yes & No \\
Month FE & Yes & 500,993 & $28,307,707$ \\
N & 500,993 & 0.660 & 0.807 \\
$\mathrm{R}^{2}$ & 0.856 & &
\end{tabular}

Note: The table presents the effect of peer comparison on water consumption. Columns (1) and (2) compare the group mean water consumption and within group standard deviation before and after the bill update, where each flat type within an HDB block constitutes a comparison group. Column (3) compares monthly water consumption for accounts that consumes above the group mean before and after the bill update, relative to the accounts that consumes below the group mean. All models include weather and pollution controls. Columns (1) and (2) in both Panels include block by flat-type fixed effects, year fixed effects and month fixed effect. Column (3) includes account fixed effects and year-month fixed effects. The standard errors are two-way clustered by block and year-month. ${ }^{*} \mathrm{p}<0.1,{ }^{* *} \mathrm{p}<0.05,{ }^{* * *} \mathrm{p}<0.01$. Standard error in parenthese 


\section{Supplementary information}

\section{A. Robustness checks on the average effect of efficiency improvements}

For robustness checks, we consider (1) alternative cut-off for project completion; (2) alternative samples; (3) alternative clustering for standard errors.

As the exact timing of project completion for each flat is unknown, we use 18-month post the announcement of a successful poll as a proxy in our baseline analysis. Using a more conservative cut-off, time of billing, we find a similar (3.4\%) reduction in water consumption for the treatment group as shown in Table A.1 column (2). Note that it could take up to two years from the time of project completion to the time a household receives the bill, hence the estimated effect size using the time of billing as the cut-off is expected to be smaller.

In our baseline analysis, we use all flats that did not implement or complete HIP as the control group. However, there may be a concern that HDB flats built during different times have inherent differences in their characteristics, leading to biased estimates on the effect of HIP. To address this concern, we restrict the sample step-by-step based upon the year of construction of the HDB flats and re-estimate equation (1) using these alternative samples. The estimates are shown in Table A.3 columns (2) to (6). First, we restrict the sample to HDB flats built before 2008. In 2008, the Mandatory Water Efficiency Labelling Scheme was introduced and the HDB flats built after 2008 were required to comply with this standard and may differ in their water efficiency level. If this is the case, including flats built after 2008 as part of the control group would lead to over-estimation of the effect of HIP; however, as shown in Table A.3 column (2), the estimate using the restricted sample does not differ from our baseline estimate. Second, we restrict the sample to the flats that qualify for the first (built before 1986) and second (built before 1997) phase of HIP, respectively. This is to eliminate the concern that the HIP eligibility cut-off may be correlated with water efficiency levels of HDB flats, although this is not likely the case since efficiency improvements was not the primary aim of HIP. As shown in Table A.3 columns (3) and (4), the estimates using samples restricted to flats built before 1997 and 1986 are 3.3\%, only marginally lower than that of the baseline estimate. Third, we further exclude HDB flats built before 1970 to avoid the effect of HIP being skewed by really old flats with potentially extreme efficiency gains. As shown in Table A.3 column (5), the estimated effect remains as 3.3\%. Last, we restrict the sample to flats built in 
1986 and 1987 only or just around the eligibility cut-off for the first phase of HIP. This is to ensure that HIP is the main differentiating factor between the treatment and control group while other sample characteristics are similar. The normalized differences between the treatment and control groups for each alternative sample are presented in Table A.2. We observe in Table A.3 column (6) that the estimate is $3.0 \%$, slightly lower than that of the baseline sample.

For the remaining concern that the flats that completed HIP may have different characteristics or pre-HIP water efficiency level as compared to the ones that did not implement or complete HIP, we restrict our sample to HIP flats only. Exploiting the variation caused by the staggered timing of HIP completion, we estimate the effect of HIP on residential water consumption to be $3.3 \%$, as shown in Table A.3 column (7).

As an additional robustness check, we relax the sample restriction by including the top and bottom $1 \%$ observations in monthly water consumption in our sample. As shown in Table A.3 column (8), there is only a slight increase in the effect size from $3.5 \%$ in the baseline sample to $3.7 \%$ in the alternative sample without restriction on extreme values.

Standard errors in the baseline estimation are two-way clustered by block and year-month. Results using alternative clustering methods are included in Table A.4. 
Table A.1: Effect of HIP on water consumption using alternative cut-off for project completion

Dependent variable: Log of water consumption

$\begin{array}{lcc}\text { HIP*Completed } & \begin{array}{l}-0.035^{* * *} \\ (0.002)\end{array} \\ \text { HIP*Billed } & & -0.034^{* * *} \\ & & (0.002) \\ \text { Weather control } & \text { Yes } & \text { Yes } \\ \text { Pollution control } & \text { Yes } & \text { Yes } \\ \text { Group time trend } & \text { Yes } & \text { Yes } \\ \text { Account FE } & \text { Yes } & \text { Yes } \\ \text { Year-month FE } & \text { Yes } & \text { Yes } \\ \text { N } & 98,291,320 & 98,291,320 \\ \mathrm{R}^{2} & 0.740 & 0.740\end{array}$

Note: This table presents the average intent-to-treat effect of HIP on water consumption for the treatment group post project completion, relative to the control group, using alternative cut-off for project completion. The dependent variable is log of monthly water consumption. HIP is an indicator variable that takes the value of 1 for the treatment group; Completed is an indicator variable that takes the value of 1 for time periods post project completion; Billed is an indicator variable that takes the value of 1 for time periods post billing. Column (1) shows the baseline estimates and column (2) uses billing date as an alternative cutoff for project completion. All models include weather and pollution controls, group specific linear time trend, account fixed effects and year-month fixed effects. The standard errors shown in parentheses are two-way clustered by block and year-month. $* \mathrm{p}<0.1, * * \mathrm{p}<0.05, * * * \mathrm{p}<0.01$. 
Table A.2: Normalized difference in descriptive statistics for alternative samples

\begin{tabular}{|c|c|c|c|c|c|}
\hline & (1) & (2) & (3) & (4) & $(5)$ \\
\hline & $\leq 2008$ & $\leq 1997$ & $\leq 1986$ & $1971-86$ & $1986-87$ \\
\hline \multicolumn{6}{|l|}{ Panel A: Water consumption } \\
\hline Mean before HIP $\left(\mathrm{m}^{3}\right)$ & 0.02 & 0.01 & -0.18 & -0.13 & -0.01 \\
\hline \multicolumn{6}{|l|}{ Panel B: Characteristics } \\
\hline \multicolumn{6}{|l|}{ Year of construction } \\
\hline Before 1980 & -0.12 & 0.07 & 0.85 & 0.66 & \\
\hline $1980-1983$ & -0.70 & -0.64 & -0.46 & -0.39 & \\
\hline 1984-1986 & -0.89 & -0.79 & -0.48 & -0.35 & \\
\hline $1987-1997$ & 1.06 & 1.42 & & & \\
\hline After 1997 & 0.86 & & & & \\
\hline \multicolumn{6}{|l|}{ Flat type } \\
\hline 1-/2-room & 0.27 & 0.34 & 0.59 & 0.47 & 0.60 \\
\hline 3-room & -0.58 & -0.42 & 0.05 & -0.02 & -0.05 \\
\hline 4-room & -0.02 & -0.06 & -0.33 & -0.21 & 0.18 \\
\hline 5-room and Executive & 0.47 & 0.35 & -0.11 & -0.02 & -0.15 \\
\hline \multicolumn{6}{|l|}{ Demographics } \\
\hline Mean family size & -0.07 & -0.05 & -0.15 & -0.07 & 0.01 \\
\hline Mean prop. of males & 0.114 & 0.07 & -0.16 & 0.06 & 0.12 \\
\hline Mean prop. of Chinese & 0.05 & -0.05 & 0.03 & 0.01 & -0.16 \\
\hline Mean prop. of elderly & -0.45 & -0.22 & 0.78 & 0.59 & -0.06 \\
\hline Mean prop. of young adults & 0.12 & -0.24 & -0.27 & -0.22 & 0.10 \\
\hline \multicolumn{6}{|l|}{ Weather and pollution } \\
\hline Mean temperature $\left(\mathrm{C}^{\circ}\right)$ & -0.03 & -0.02 & 0.07 & 0.06 & 0.07 \\
\hline Mean no. of rainy days & 0.01 & 0.00 & -0.02 & -0.01 & -0.02 \\
\hline Mean PSI & 0.00 & 0.00 & 0.00 & 0.00 & 0.00 \\
\hline Observations & $86,732,067$ & $69,771,942$ & $46,002,072$ & $41,526,217$ & $6,500,267$ \\
\hline
\end{tabular}

Note: This table presents the normalized difference in the group mean for HIP and non-HIP flats for alternative samples. Columns (1) to (5) use HDB flats built before 2008; HDB flats built before 1997 or qualifies for HIP; HDB flats built before 1986 or qualifies for the first phase of HIP; HDB flats built between 1971 to 1986; and HDB flats built in 1986/87 or around the cut-off for the first phase, respectively. 
Table A.3: Effect of HIP on water consumption using alternative samples

\begin{tabular}{|c|c|c|c|c|c|c|c|c|}
\hline Dependent variable: & (1) & (2) & (3) & (4) & $(5)$ & (6) & (7) & (8) \\
\hline Log of water consumption & Baseline & $\leq 2008$ & $\leq 1997$ & $\leq 1986$ & $1971-86$ & $1986-87$ & HIP only & $\mathrm{w} /$ extremes \\
\hline HIP*Completed & $\begin{array}{l}-0.035^{* * *} \\
(0.002)\end{array}$ & $\begin{array}{l}-0.035^{* * *} \\
(0.002)\end{array}$ & $\begin{array}{l}-0.033^{* * *} \\
(0.002)\end{array}$ & $\begin{array}{l}-0.033^{* * *} \\
(0.002)\end{array}$ & $\begin{array}{l}-0.033^{* * *} \\
(0.001)\end{array}$ & $\begin{array}{l}0.030 * * * \\
(0.002)\end{array}$ & $\begin{array}{l}-0.033^{* * *} \\
(0.002)\end{array}$ & $\begin{array}{l}-0.037 * * * \\
(0.002)\end{array}$ \\
\hline Weather control & Yes & Yes & Yes & Yes & Yes & Yes & Yes & Yes \\
\hline Pollution control & Yes & Yes & Yes & Yes & Yes & Yes & Yes & Yes \\
\hline Group time trend & Yes & Yes & Yes & Yes & Yes & Yes & No & Yes \\
\hline Account FE & Yes & Yes & Yes & Yes & Yes & Yes & Yes & Yes \\
\hline Year-month FE & Yes & Yes & Yes & Yes & Yes & Yes & Yes & Yes \\
\hline $\mathrm{N}$ & $98,291,320$ & $86,732,067$ & $69,771,942$ & $46,002,072$ & $41,526,217$ & $6,500,267$ & $24,655,772$ & $99,859,740$ \\
\hline $\mathrm{R}^{2}$ & 0.74 & 0.74 & 0.753 & 0.752 & 0.752 & 0.748 & 0.749 & 0.717 \\
\hline
\end{tabular}

Note: This table presents the average intent-to-treat effect of HIP on water consumption for the treatment group post project completion, relative to the control group, using alternative samples. The dependent variable is $\log$ of monthly water consumption. HIP is an indicator variable that takes the value of 1 for the treatment group; Completed is an indicator variable that takes the value of 1 for time periods post project completion.

Column (1) shows the baseline estimates using the full sample; column (2) uses HDB flats built before 2008 when Mandatory Water Efficiency Standards was implemented; column (3) uses HDB flats built before 1997 or qualifies for HIP; column (4) uses HDB flats built before 1986 or qualifies for the first phase of HIP; column (5) uses HDB flats built between 1971 to 1986 to exclude very old flats; column (6) uses flats built in 1986/87 or around the cut-off for the first phase; column (7) uses only HDB flats that has completed HIP; column (8) removes the restriction on baseline sample by including the top and bottom 1\% observation in monthly water consumption. All models include weather and pollution controls, group specific linear time trend, account fixed effects and year-month fixed effects. The standard errors shown in parentheses are twoway clustered by block and year-month. $* \mathrm{p}<0.1, * * \mathrm{p}<0.05, * * * \mathrm{p}<0.01$. 
Table A.4: Alternative clustering

\begin{tabular}{lcccc}
\hline Dependent variable: & $(1)$ & $(2)$ & $(3)$ & (4) \\
Log of water consumption & \multicolumn{2}{c}{ Two-way } & \multicolumn{2}{c}{ One-way } \\
& Account, Year-month & Block, Year-month & Account & Block \\
& & & & \\
& & & \\
HIP*Completed & $-0.035^{* * *}$ & $-0.035^{* * *}$ & $-0.035^{* * *}$ & $-0.035^{* * *}$ \\
& $(0.002)$ & $(0.002)$ & $(0.001)$ & $(0.001)$ \\
Weather control & Yes & Yes & Yes & Yes \\
Pollution control & Yes & Yes & Yes & Yes \\
Group time trend & Yes & Yes & Yes & Yes \\
Account FE & Yes & Yes & Yes & Yes \\
Year-month FE & Yes & Yes & Yes & Yes \\
$\mathrm{N}$ & $98,291,320$ & $98,291,320$ & $98,291,320$ & $98,291,320$ \\
$\mathrm{R}^{2}$ & 0.740 & 0.740 & 0.740 & 0.740
\end{tabular}

Note: This table presents the average effect of HIP on water consumption with alternative clustering for standard error. The dependent variable is log of monthly water consumption. HIP is an indicator variable that takes the value of 1 for the treatment group; Completed is an indicator variable that takes the value of 1 for time periods post project completion. Standard errors are two-way clustered by account and yearmonth for column (1), and by block and year-month for column (2); they are one-way clustered by account for column (3) and by block for column (4). All models include weather and pollution controls, group specific linear time trend, account fixed effects and year-month fixed effects. ${ }^{*} \mathrm{p}<0.1,{ }^{* *} \mathrm{p}<0.05, * * * \mathrm{p}$ $<0.01$. Standard error in parentheses. 


\section{B. Additional figures and tables}

Figure B.1: Map of HDB blocks by HIP status

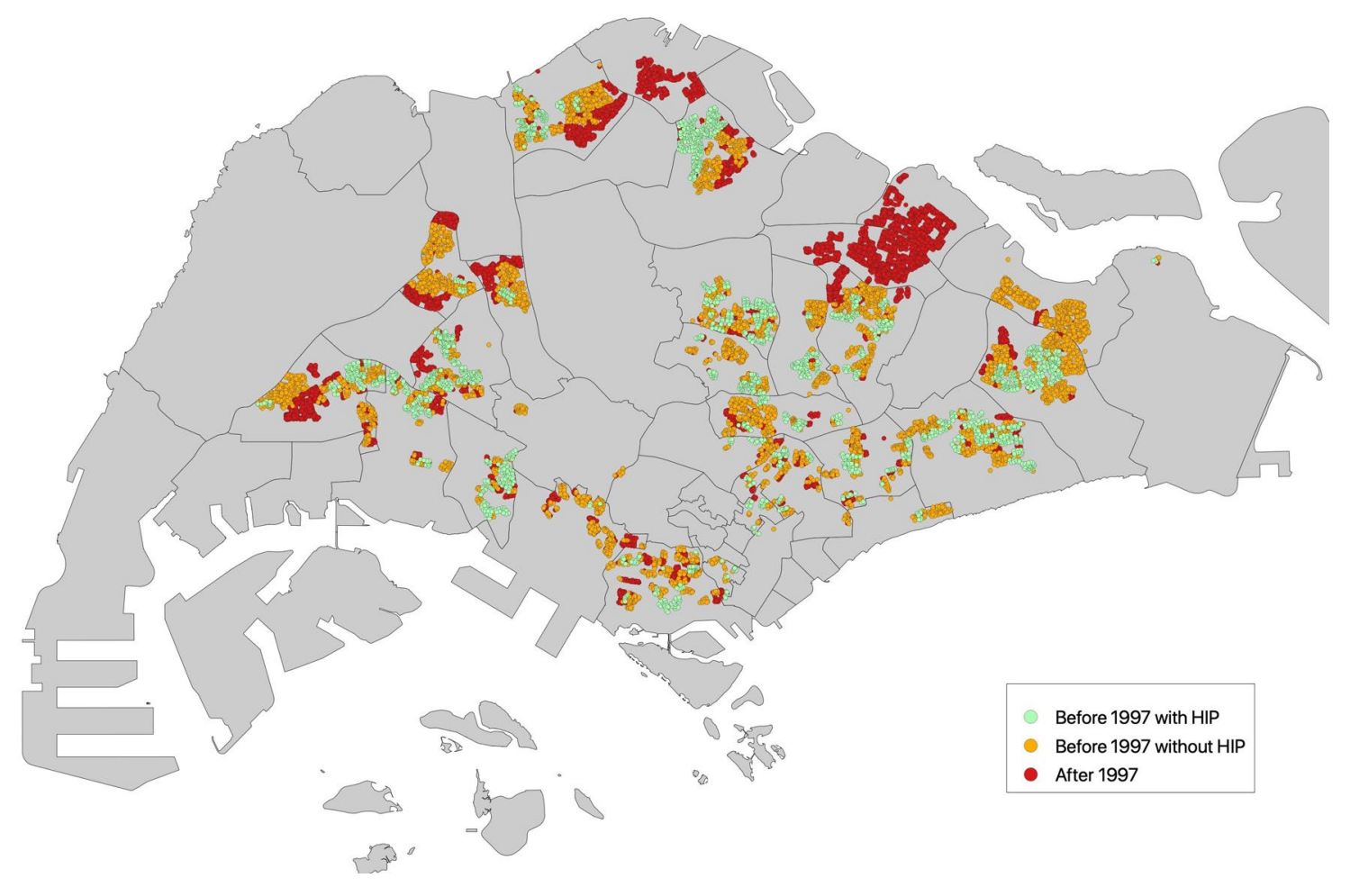

Note: The map shows the location of all HDB blocks in Singapore. The green circles represent HDB blocks that completed HIP by December 2019; the yellow circles represent HDB blocks that qualifies (i.e. built before 1997) for HIP but did not go through or complete the upgrade by December 2019; the red circles represent HDB blocks that do not qualify for HIP (i.e. built after 1997). 
Figure B.2: Distribution of HDB flats by year of HIP completion

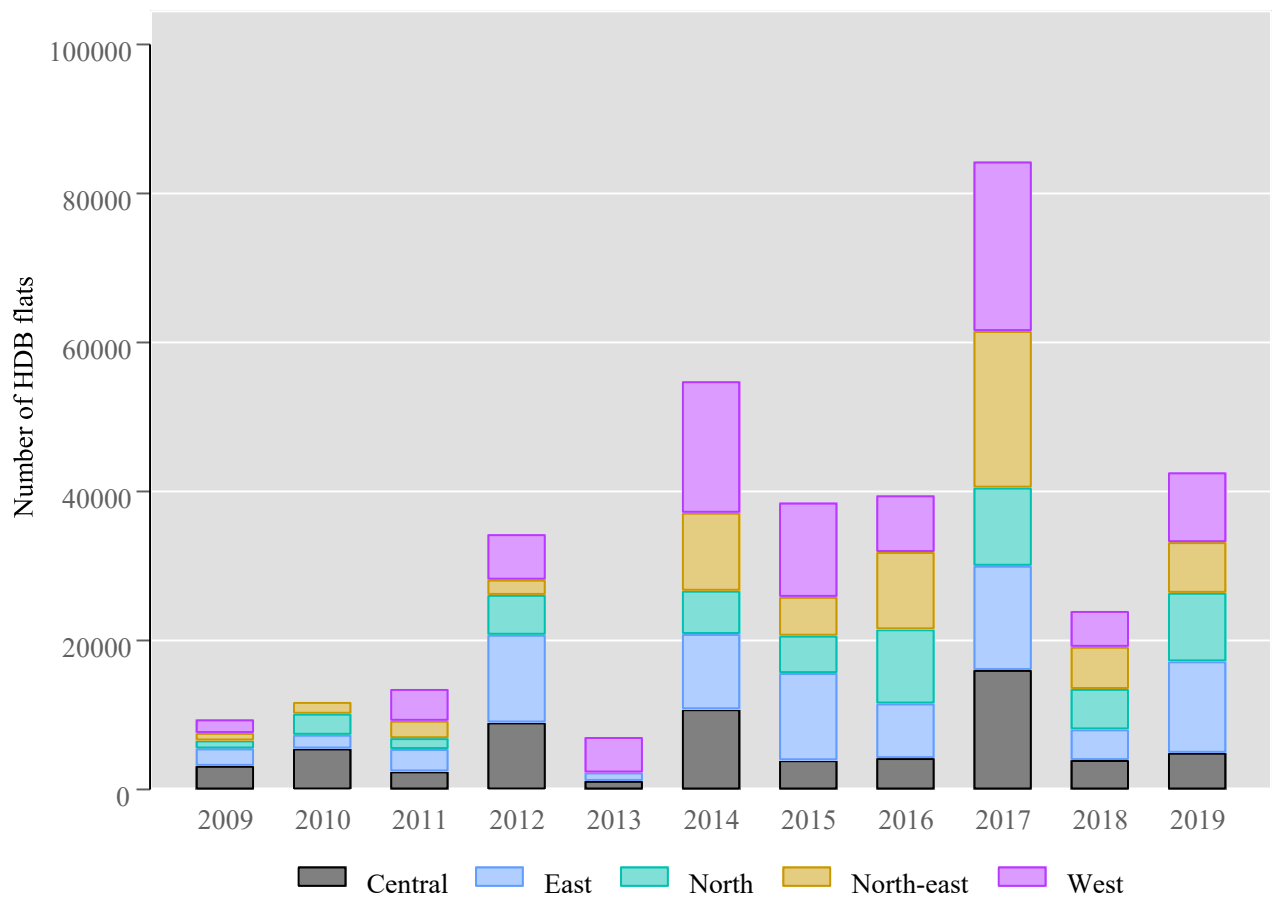

Note: The figure shows the number of HDB flats in each region (Central, East, North, Northeast, and West) by year of HIP completion. Projects are considered complete 18 months after the announcement of a successful poll. from the Government of Singapore. 
Figure B.3: Trend and spatial variation in temperature, rainfall, and air pollution
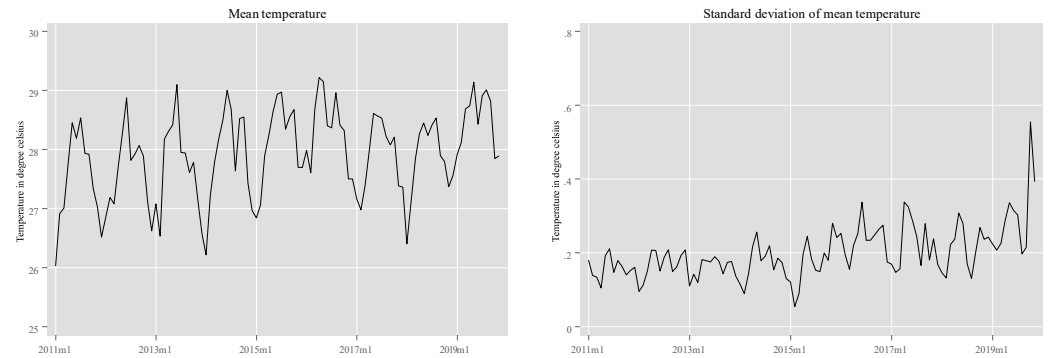

(a) Mean and standard deviation in temperature
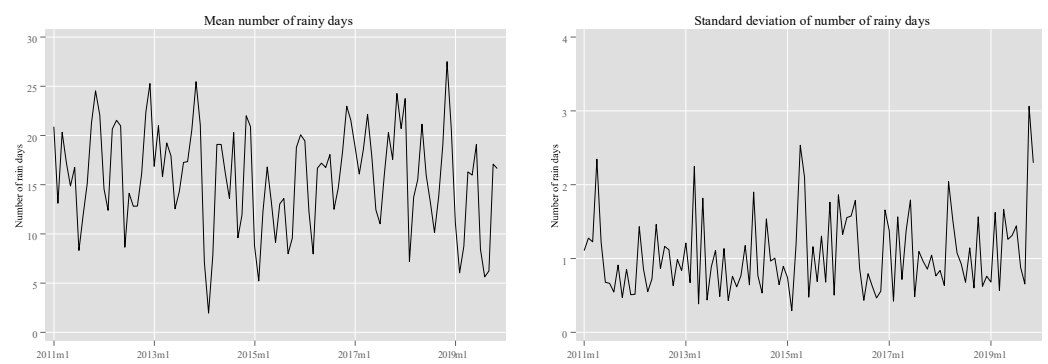

(b) Mean and standard deviation in number of rainy days
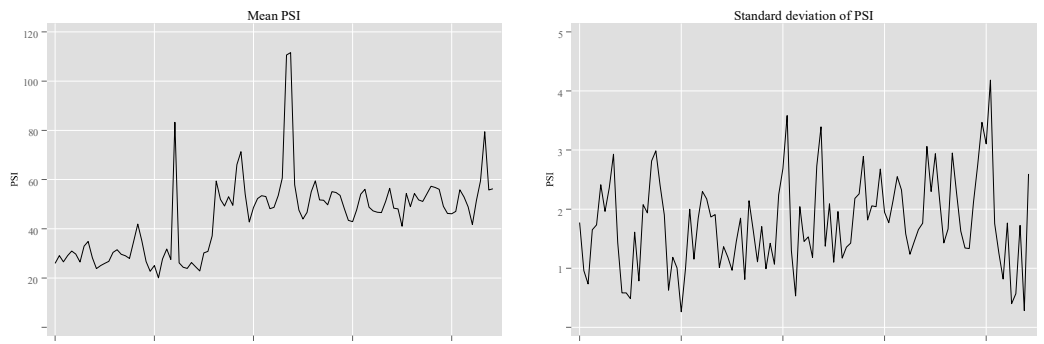

(c) Mean and standard deviation in PSI

Note: The figures show the trend and spatial variation (in terms of standard deviation) in monthly mean temperature (Panel (a)), number of rainy days (Panel (b)), and PSI (Panel (c)) from January 2011 to December 2019. 
Figure B.4: Evolutionary effect of HIP using alternative samples

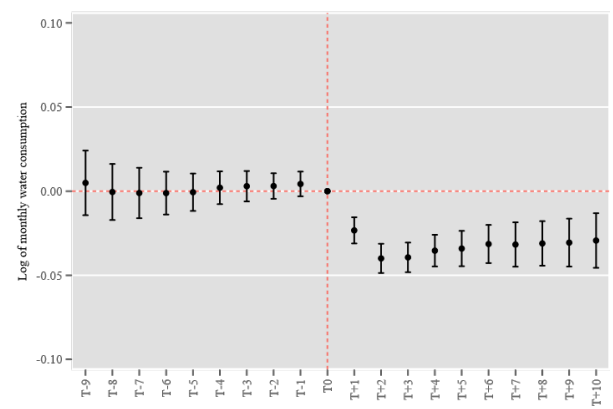

(a) Before 2008

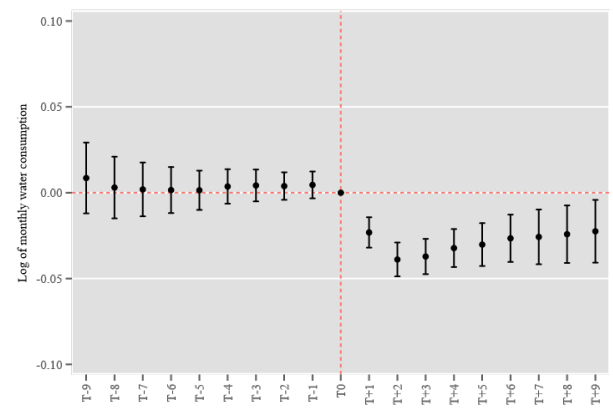

(c) Before 1986

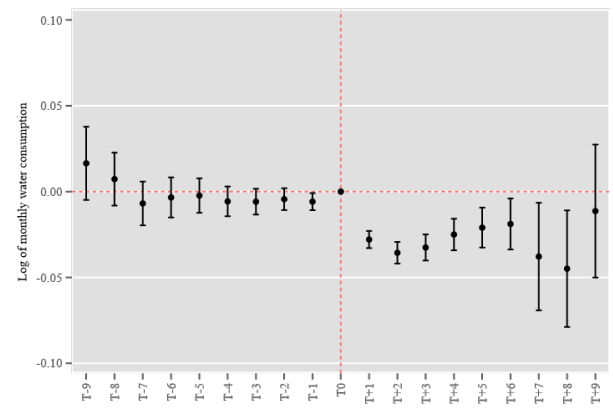

(e) $1986-1987$

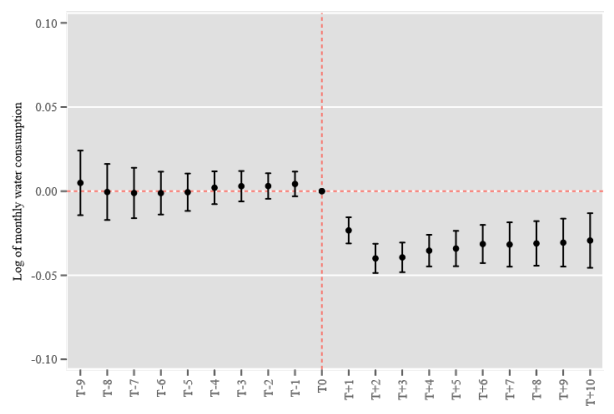

(b) Before 1997

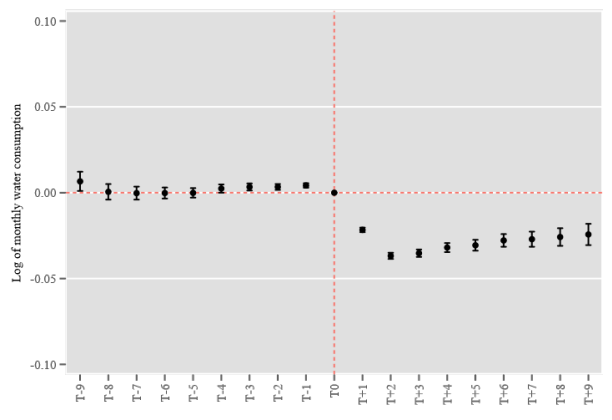

(d) $1971-1986$

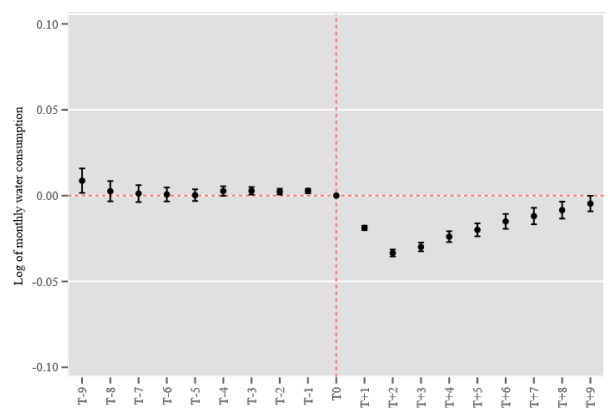

(f) HIP flats only

Note: The figures show, for each alternative sample, the coefficients and corresponding $95 \%$ confidence intervals for the difference in water consumption between flats that completed and did not complete HIP for each 12-month period after HIP completion. Sub-figures (a) to (f) use HDB flats built before 2008; HDB flats built before 1997 or qualifies for HIP; HDB flats built before 1986 or qualifies for the first phase of HIP; HDB flats built between 1971 to 1986; HDB flats built in 1986/87 or around the cut-off for the first phase; and HDB flats that has completed HIP only, respectively. 
Figure B.5: Number of observations by housing characteristics and water demand

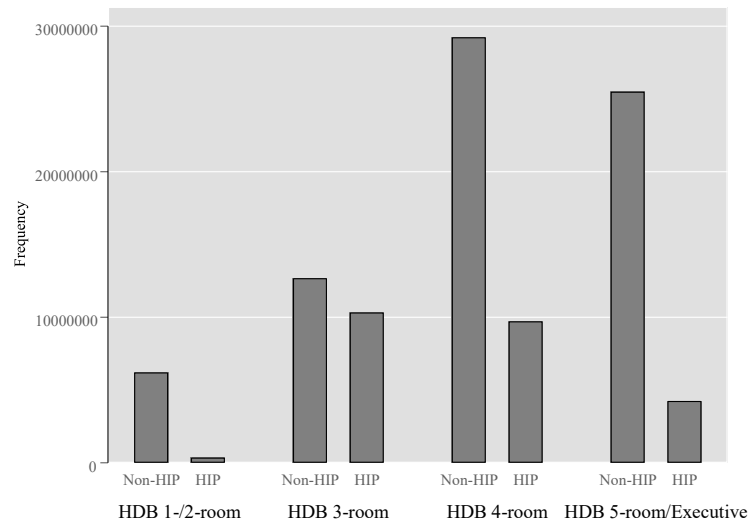

(a) By flat type

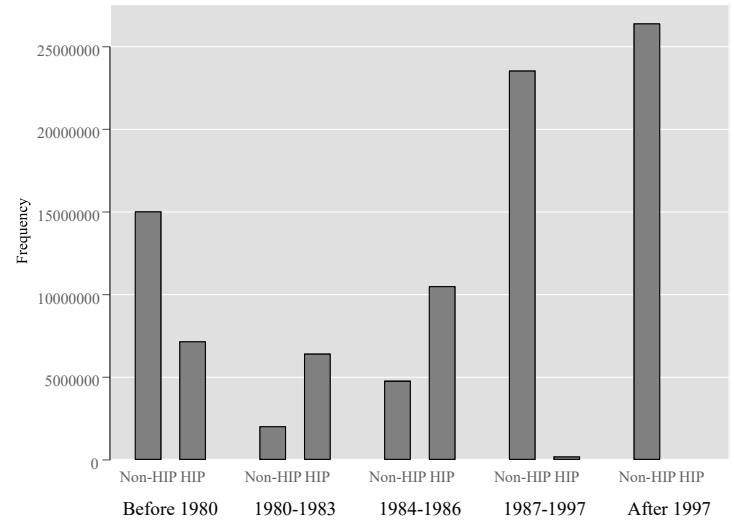

(b) By year of construction

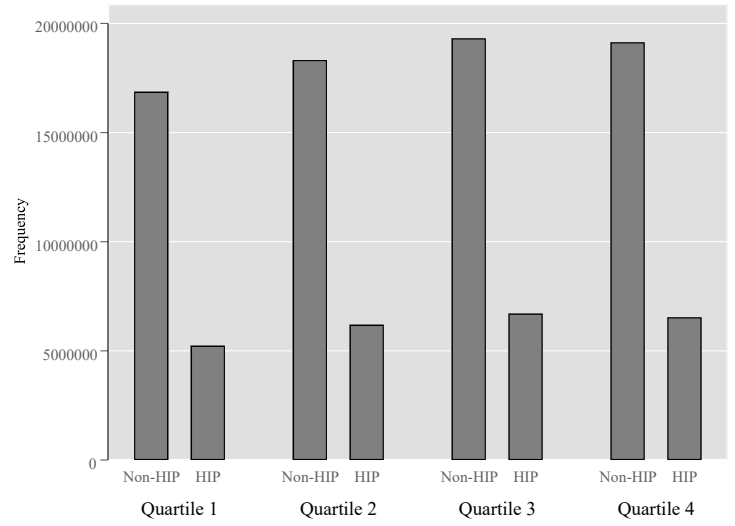

(c) By water consumption quartile

Note: The figures show the number of observations for treatment and control groups by flat type (Panel (a)), year of construction (Panel (b)) and water consumption quartile (Pane (c)). 
Figure B.6: Sample distribution by water consumption quartile and housing characteristics

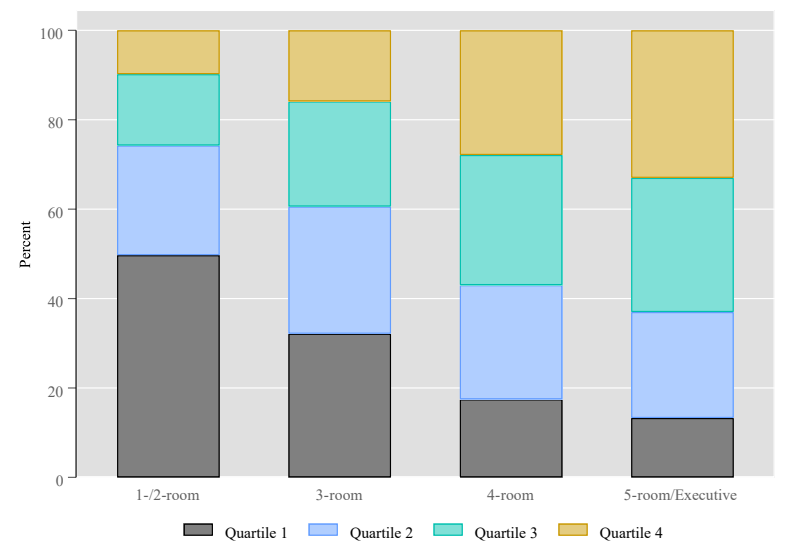

(a) By flat type

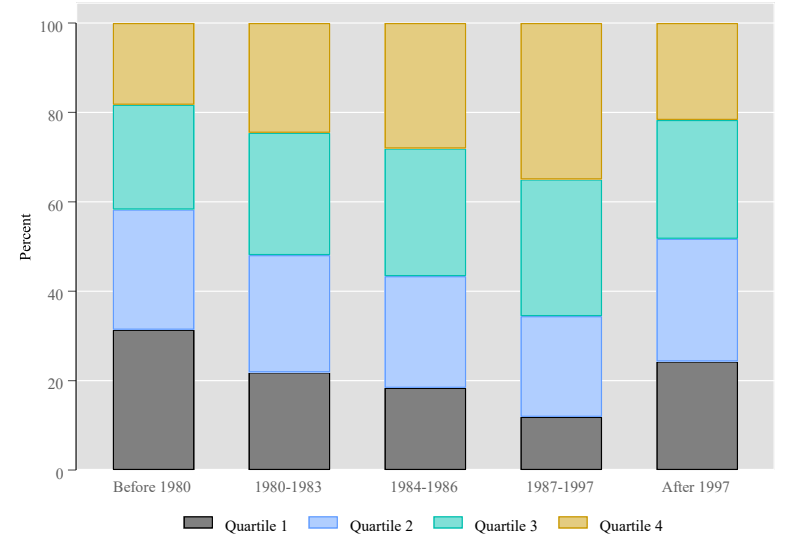

(b) By year of construction

Note: The figure shows the proportion of observations for each water consumption quartile by flat type (Panel (a)) and year of construction (Panel (b)). 
Figure B.7: Heterogeneous effect of HIP by consumption quartile and housing characteristics

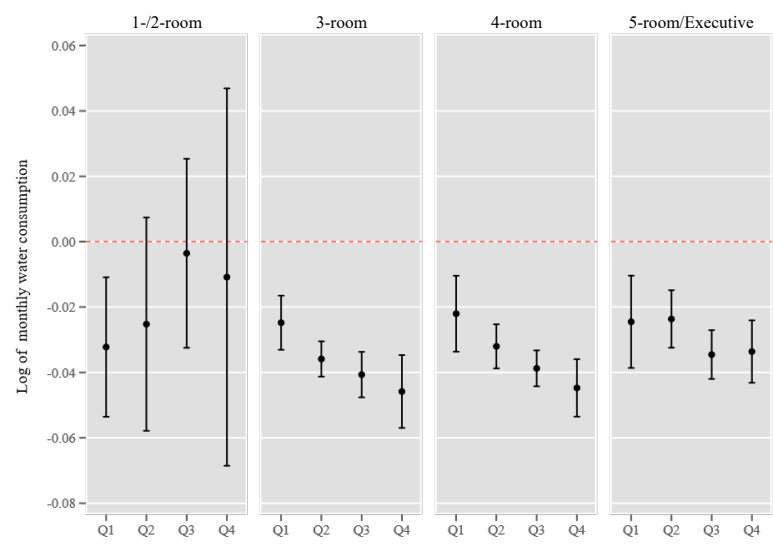

(a) By flat type

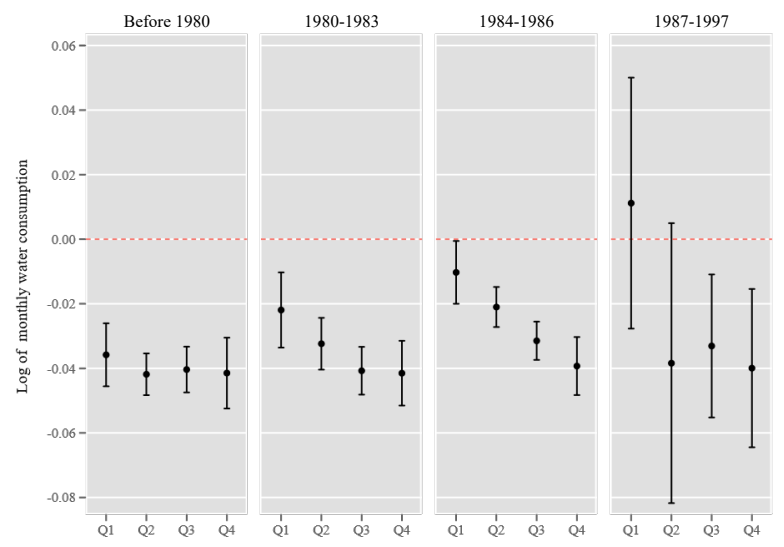

(a) By year of construction

Note: The figures show the coefficients and corresponding 95\% confidence intervals for the effect of HIP on monthly water consumption by water consumption quartile and flat type (Panel (a)), and water consumption quartile and year of construction (Panel (b)). 
Figure B.8: Number of observations by block-level demographics

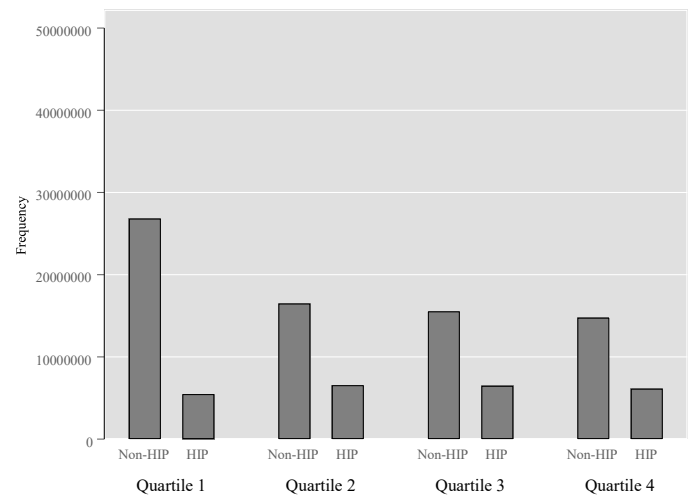

(a) By family size

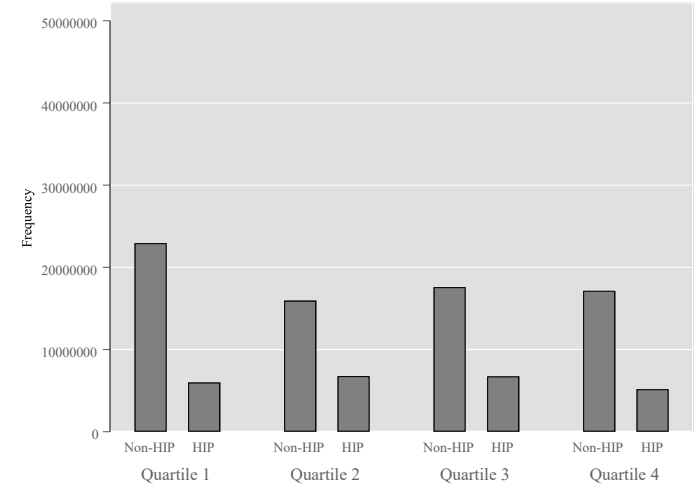

(b) By proportion of male

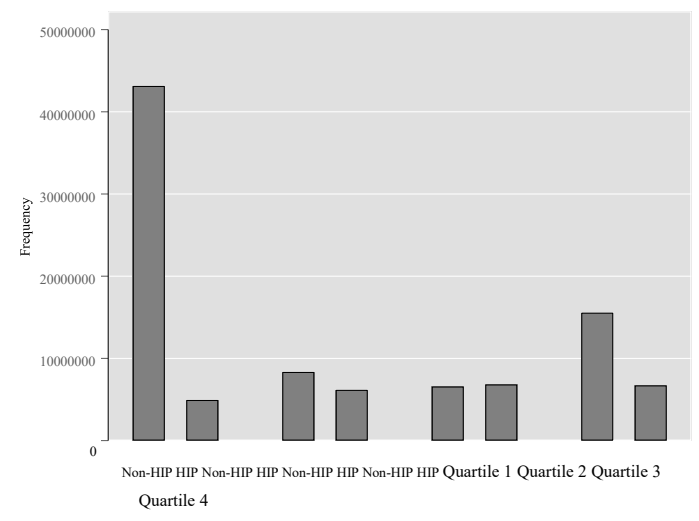

(d) By proportion of elderly

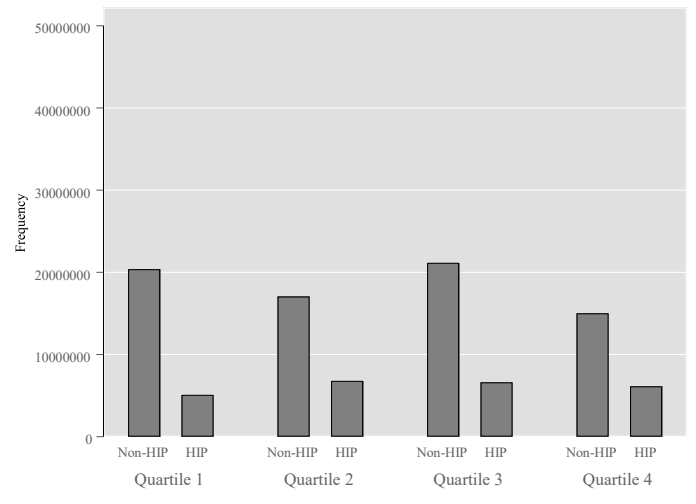

(c) By proportion of Chinese

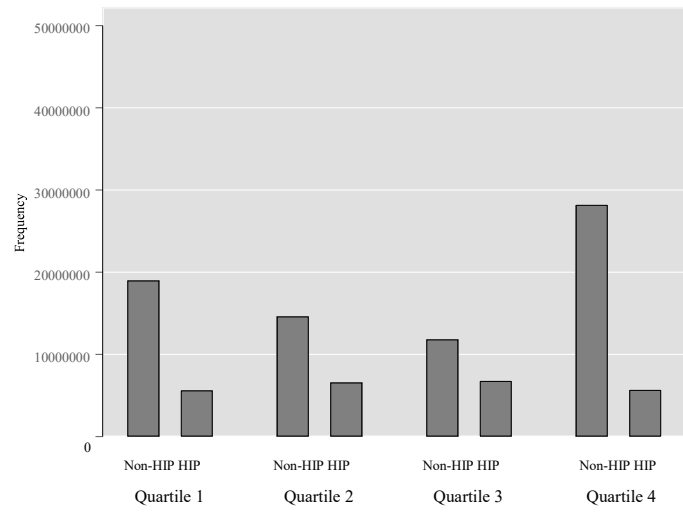

(e) By proportion of young family

Note: The figures show the number of observations for treatment and control groups by quartile of blocklevel demographics, including family size (sub-figure (a)), proportion of male (sub-figure (b)), proportion of Chinese (sub-figure (c)), proportion of elderly (subfigure (d)) and proportion of young family (sub-figure (e)). 
Figure B.9: Evolutionary effect of HIP by housing characteristics and water demand
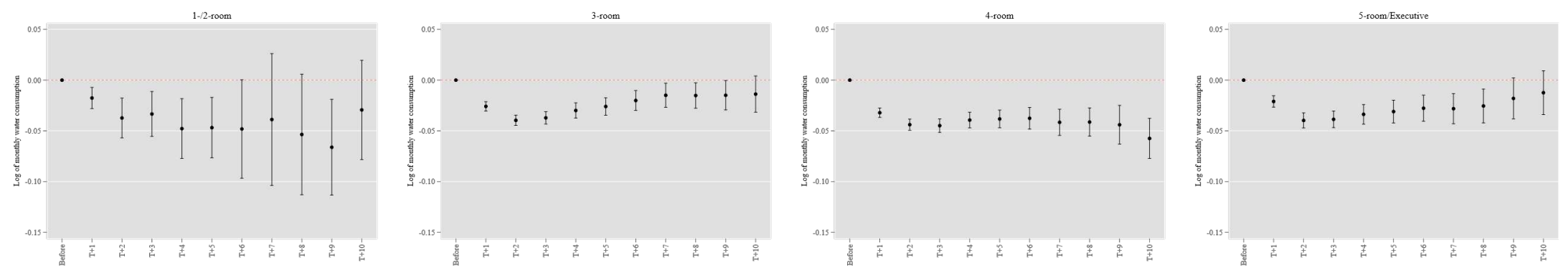

(a) By flat type
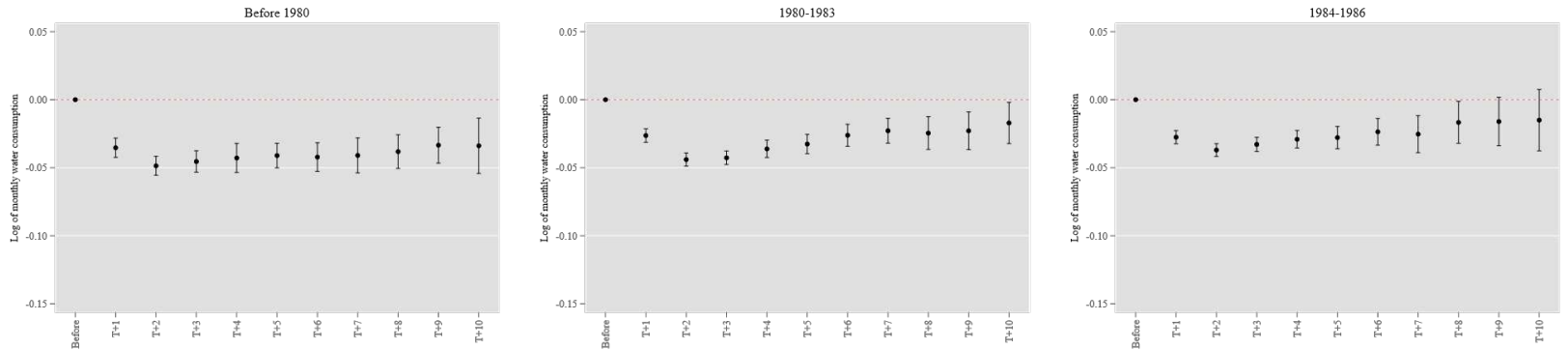

(b) By year of construction
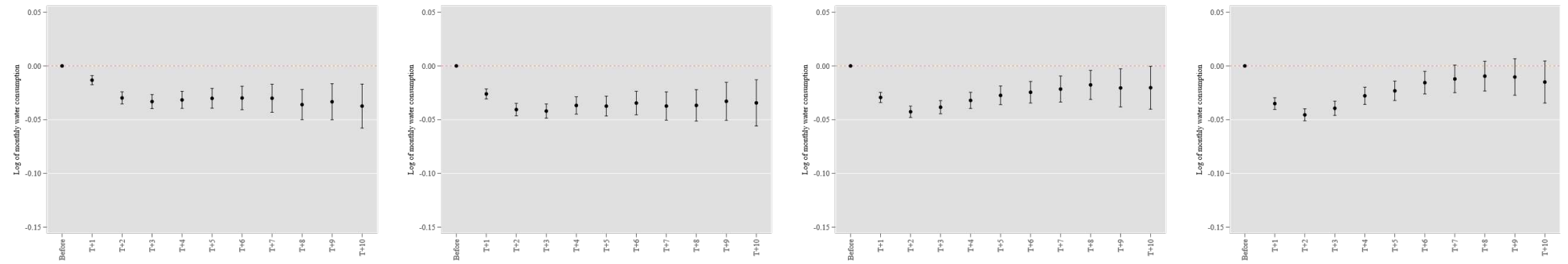

(c) By water consumption quartile

Note: The figures show, for each subgroup by flat type (Panel (a)), year of construction (Panel (b)), and water consumption quartile (Panel (c)), the coefficients and corresponding $95 \%$ confidence intervals for the difference in water consumption between flats that completed and did not complete HIP for each 12-month period after HIP completion. 
Figure B.10: Evolutionary effect of HIP by block-level demographics
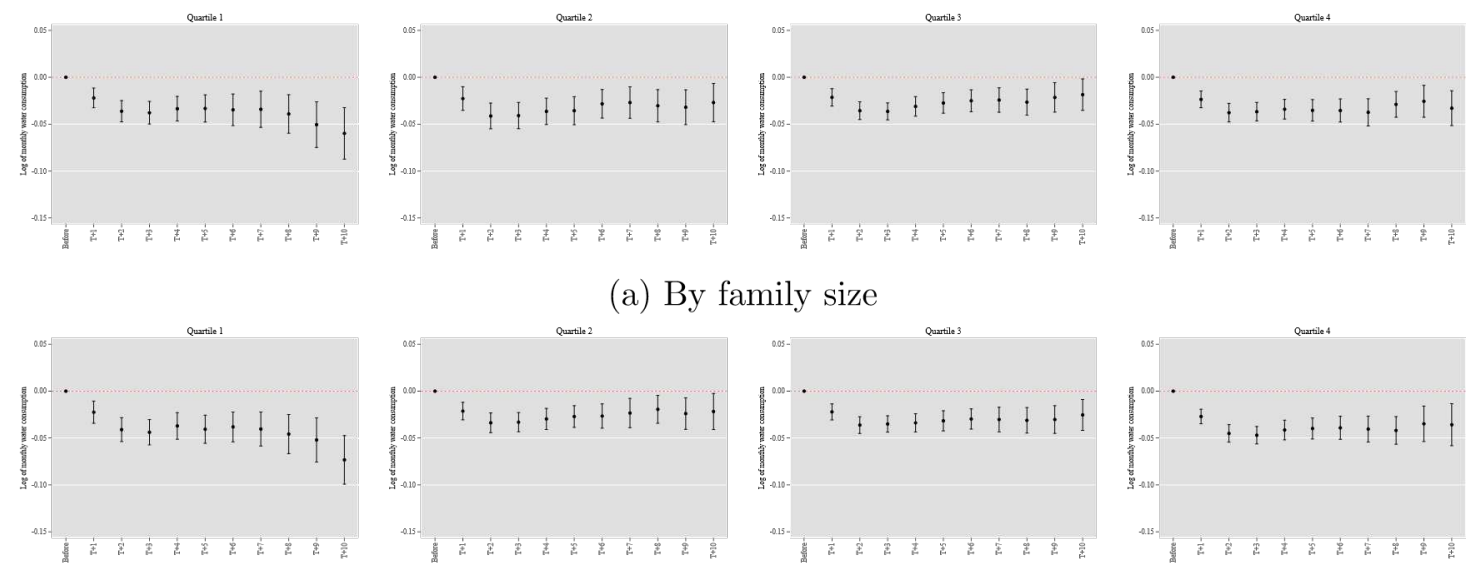

(b) By proportion of male
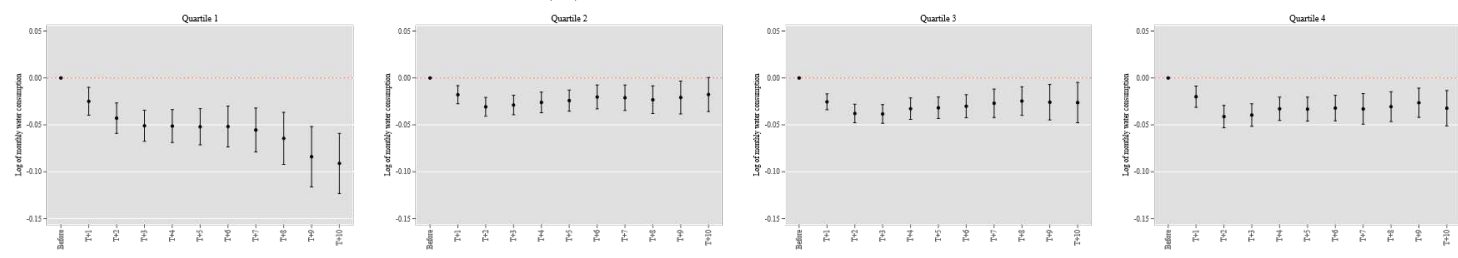

(c) By proportion of Chinese
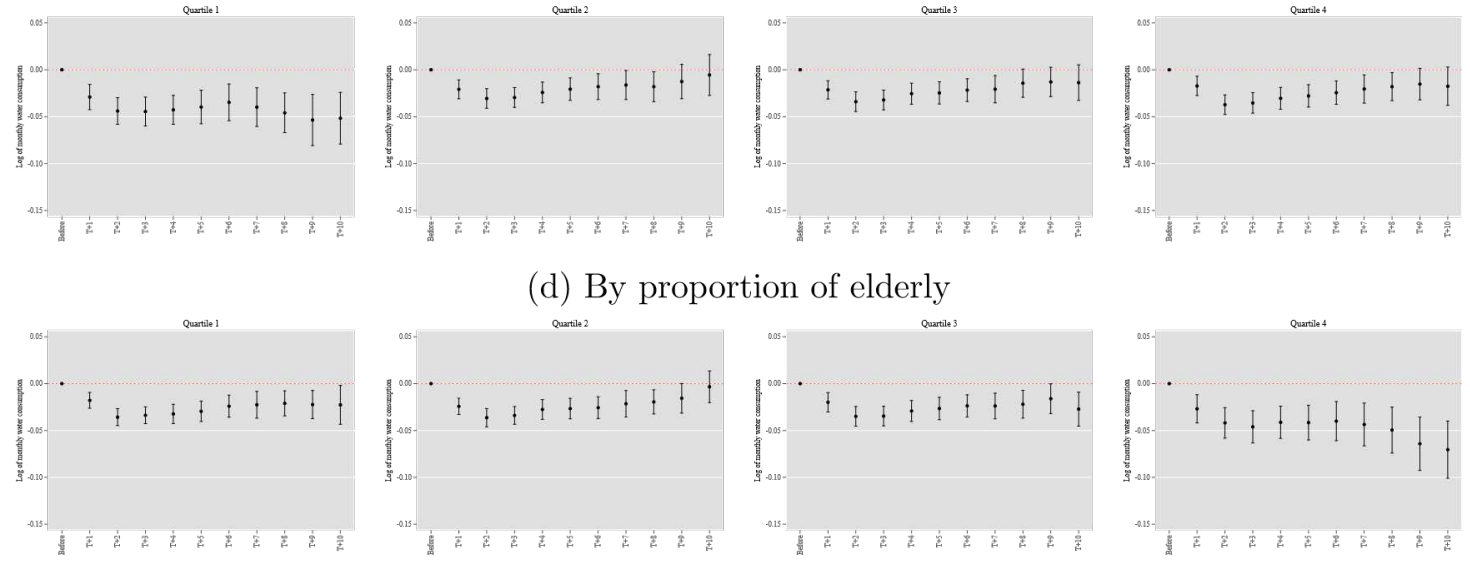

(e) By proportion of young family

Note: The figures show, for each quartile of block-level demographics, such as family size (Panel (a)), proportion of male (Panel (b)), proportion of Chinese (Panel (c)), proportion of elderly (Panel(d)), and proportion of young family (Panel(e)), the coefficients and corresponding $95 \%$ confidence intervals for the difference in water consumption between flats that completed and did not complete HIP for each 12-month period after HIP completion. 
Figure B.11: Evolutionary effect of HIP under extreme environmental conditions

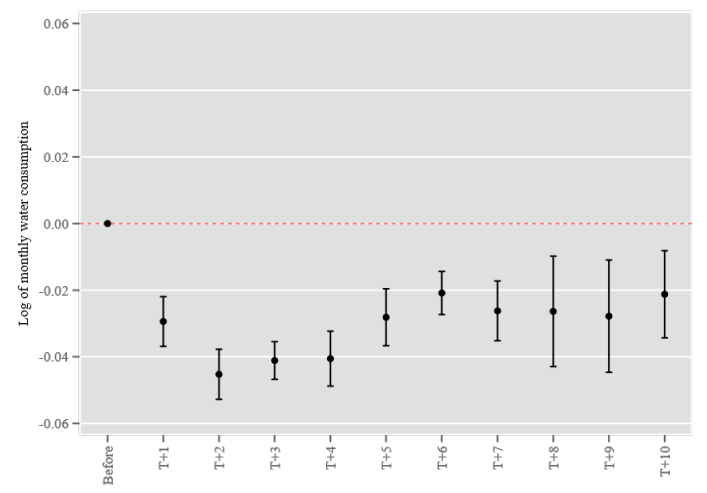

(a) Temperature

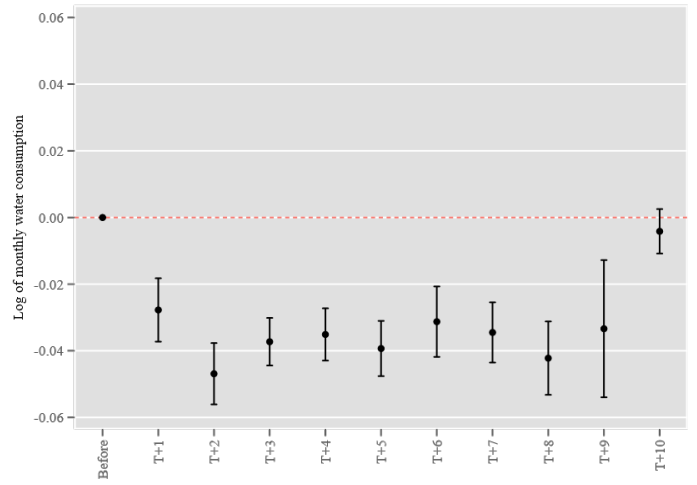

(b) Number of rainy days

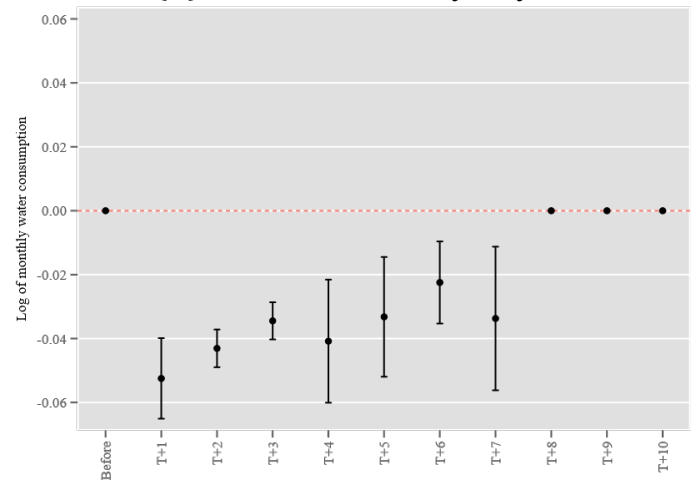

(c) PSI

Note: The figures show the coefficients and corresponding $95 \%$ confidence intervals for the interaction effect of HIP and extreme environmental conditions, such as high temperature, excessive number of rainy days and high pollution level, on monthly water consumption during each 12-month period after HIP completion. The coefficients are not estimated for time periods $T+8$ onwards in Panel (c) as no unhealthy PSI were observed during this time period. Coefficients for time periods $\mathrm{T}+8$ on wards are not estimated due to lack of observations. 
Figure B.12: Trend in mean and variation in water consumption for peer comparison

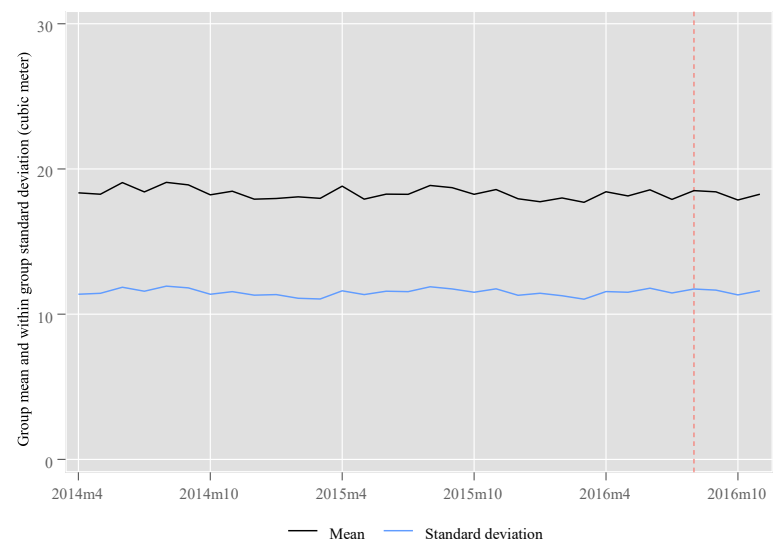

(a) Trend in mean and within group standard deviation of water consumption

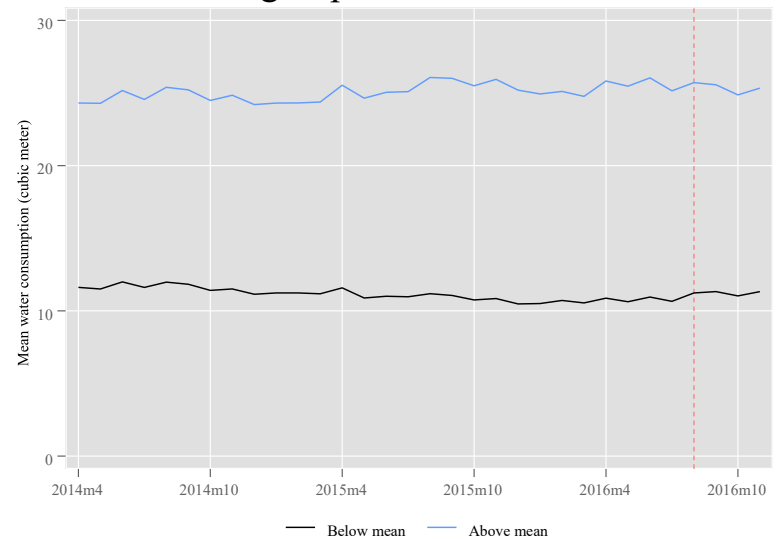

(b) Trend in mean water consumption for accounts consume above and below group mean

Note: The figures show the trend in group mean and within group standard deviation (Panel (a)), where each flat type within an HDB block constitutes a comparison group; and the trend in water consumption for accounts that consumes above and below the group mean (Panel (b)). 
Figure B.13: Evolutionary effect of peer comparison

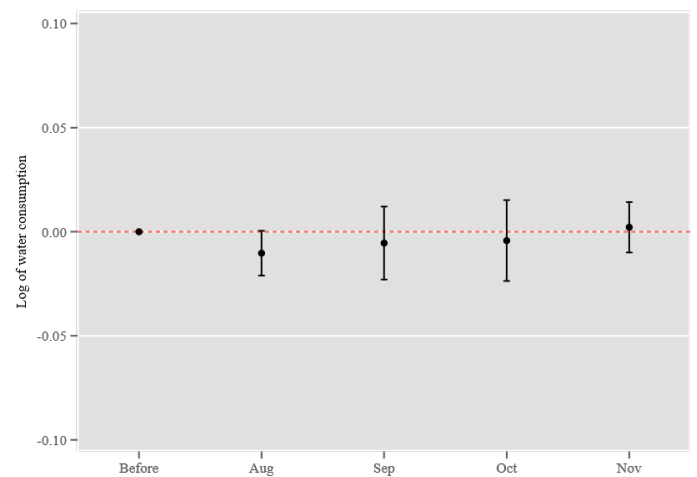

(a) Group mean water consumption

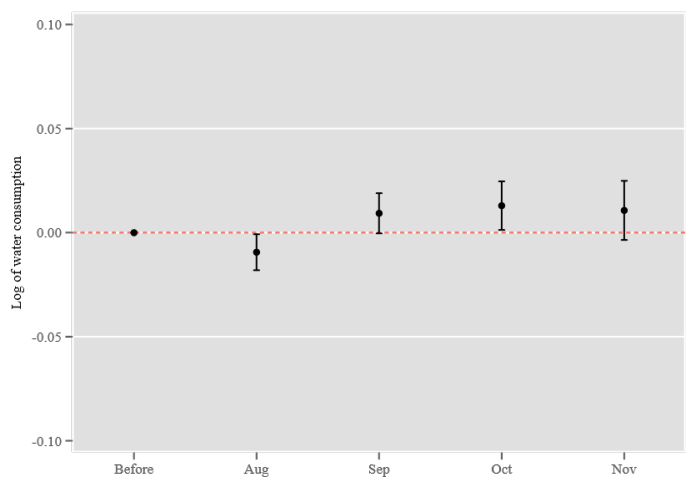

(b) Within group standard deviation

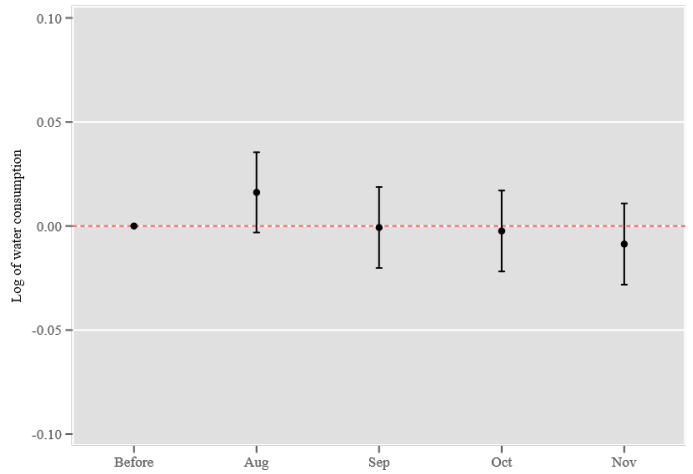

(c) Difference in mean water consumption for accounts consume above and below group mean

Note: The figures show the group mean (Panel (a)), within group standard deviation (Panel (b)) and the difference in mean water consumption for accounts consume above and below group mean (Panel (c)) for each of month after bill update as compared to the mean before bill update. 
Figure B.14: Heterogeneous effect of peer comparison on water consumption
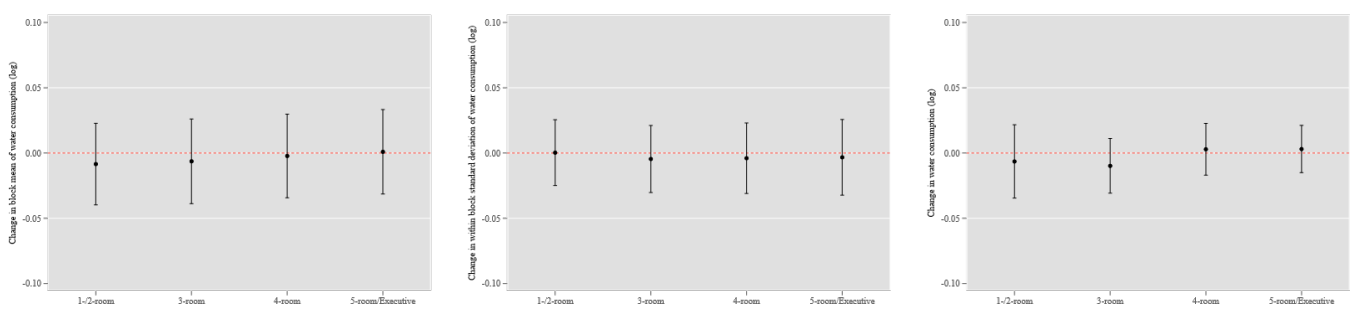

(a) By flat type
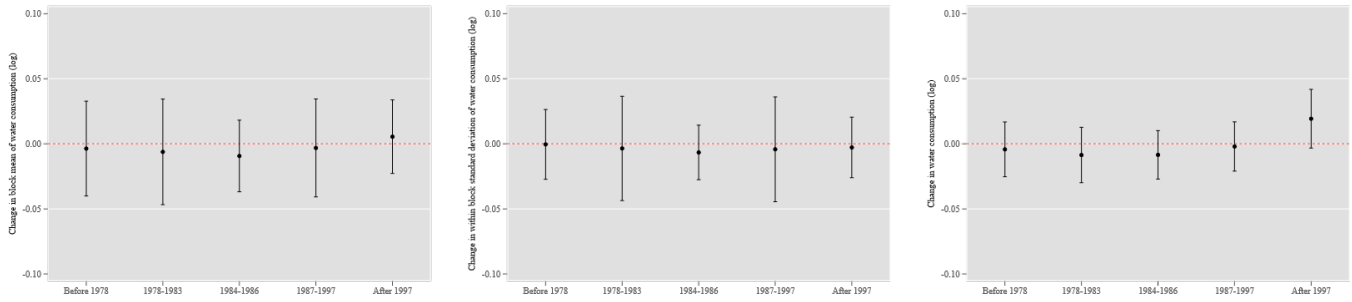

(b) By year of construction
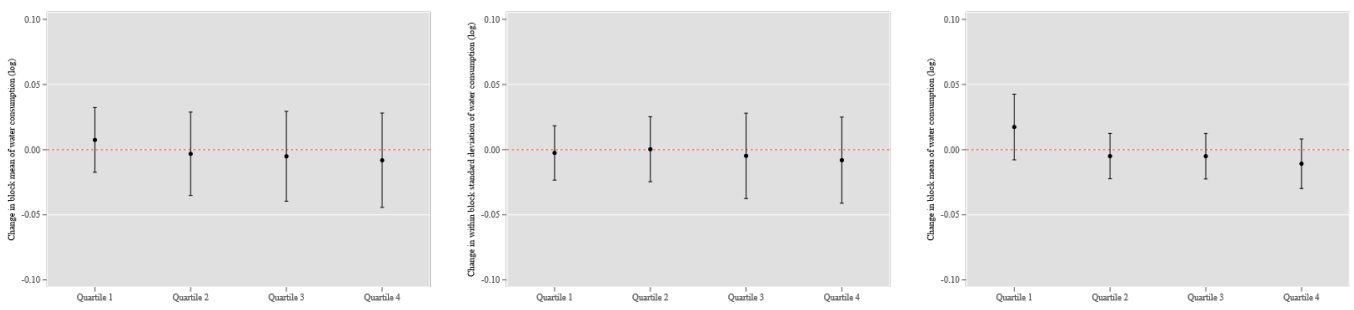

(c) By water consumption quartile

Note: The figures show the coefficients and corresponding $95 \%$ confidence intervals for the effect of peer comparison on monthly water consumption for each subgroup by estimating equation (4). Panel (a), (b) and (c) show the effects by flat type, year of construction, and water consumption quartile, respectively. 
Table B.1: Household income and cost of HIP by flat type

\begin{tabular}{ccc}
\hline Flat Type & Monthly income & Amount payable \\
\hline 1/2-room & 2,765 & $630(5 \%)$ \\
3-room & 6,497 & $630(5 \%)$ \\
4-room & 9,306 & $945(7.5 \%)$ \\
5-room & $12,712 *$ & $1,260(10 \%)$ \\
Executive & $12,712 *$ & $1,575(12.5 \%)$
\end{tabular}

Note: This table presents the average monthly household income by flat type in 2018 and the amount payable for HIP optional improvements. Data is available at https:/www.singstat .gov.sg//media/files/publications/households/pp-s25.pdf (last accessed: August 21, 2020) and https://www.gov.sg/article/5-things-you-should-know-if-your-home-is-undergoing-hip (last accessed: August 21, 2020). *Monthly income is only available for HDB 5-room and HDB Executive flats combined. 
Table B.2: Descriptive statistics

\begin{tabular}{|c|c|c|c|c|c|}
\hline & \multicolumn{2}{|l|}{ (1) } & \multicolumn{2}{|l|}{ (2) } & (3) \\
\hline & \multicolumn{2}{|c|}{ HIP } & \multicolumn{2}{|c|}{ Non-HIP } & \multirow[t]{2}{*}{ Normalized Diff } \\
\hline & Mean & SD & Mean & $\mathrm{SD}$ & \\
\hline \multicolumn{6}{|l|}{ Panel A: Water consumption } \\
\hline Mean before HIP $\left(m^{3}\right)$ & 17.24 & 10.42 & 16.80 & 10.34 & -0.04 \\
\hline Mean after HIP $\left(m^{3}\right)$ & 15.42 & 9.57 & & & \\
\hline \multicolumn{6}{|l|}{ Panel B: Characteristics } \\
\hline \multicolumn{6}{|l|}{ Year of construction } \\
\hline Before 1980 & 0.29 & 0.46 & 0.21 & 0.41 & -0.20 \\
\hline $1980-1983$ & 0.26 & 0.44 & 0.03 & 0.17 & -0.71 \\
\hline 1984-1986 & 0.43 & 0.50 & 0.07 & 0.25 & -0.93 \\
\hline 1987-1997 & 0.01 & 0.09 & 0.33 & 0.47 & 0.94 \\
\hline After 1997 & 0.00 & 0.00 & 0.37 & 0.48 & 1.07 \\
\hline \multicolumn{6}{|l|}{ Flat type } \\
\hline 1-/2-room & 0.01 & 0.12 & 0.08 & 0.28 & 0.32 \\
\hline 3-room & 0.42 & 0.49 & 0.17 & 0.38 & -0.56 \\
\hline 4-room & 0.39 & 0.49 & 0.40 & 0.49 & 0.01 \\
\hline 5-room and Executive & 0.17 & 0.38 & 0.35 & 0.48 & 0.40 \\
\hline \multicolumn{6}{|l|}{ Demographics } \\
\hline Mean family size & 3.16 & 0.68 & 2.88 & 1.05 & -0.31 \\
\hline Mean prop. of males & 0.47 & 0.04 & 0.42 & 0.14 & -0.43 \\
\hline Mean prop. of Chinese & 0.74 & 0.11 & 0.66 & 0.24 & -0.38 \\
\hline Mean prop. of elderly & 0.26 & 0.06 & 0.20 & 0.12 & -0.64 \\
\hline Mean prop. of young adults & 0.19 & 0.04 & 0.29 & 0.24 & 0.53 \\
\hline \multicolumn{6}{|l|}{ Weather and pollution } \\
\hline Mean temperature $\left(\mathrm{C}^{\circ}\right)$ & 27.93 & 0.76 & 27.93 & 0.75 & -0.01 \\
\hline Mean no. of rainy days & 15.81 & 5.26 & 15.84 & 5.26 & 0.01 \\
\hline Mean PSI & 45.02 & 16.09 & 45.66 & 15.93 & 0.04 \\
\hline Observations & $24,655,772$ & & $73,635,548$ & & $98,291,320$ \\
\hline
\end{tabular}

Note: This table provides the mean and standard deviation for monthly water consumption (Panel A), housing characteristics, demographic characteristics, and weather and pollution controls (Panel B) for the treatment group (column (1)) and control group (column (2)). Normalized differences between the group means are provided in column (3). 
Table B.3: Interaction effect of HIP and temperature, rainfall, and air pollution

\begin{tabular}{|c|c|c|c|c|c|c|c|}
\hline Dependent variable: & (1) & (2) & (3) & (4) & (5) & (6) & (7) \\
\hline Log of water consumption & $\log$ & \multicolumn{3}{|c|}{ Standardized } & \multicolumn{3}{|c|}{ Extreme } \\
\hline \multirow[t]{2}{*}{ HIP*Completed } & $-0.035 * * *$ & $-0.034 * * *$ & $-0.034 * * *$ & $-0.034 * * *$ & $-0.034 * * *$ & $-0.035 * * *$ & $-0.034 * * *$ \\
\hline & $(0.002)$ & $(0.002)$ & $(0.002)$ & $(0.002)$ & $(0.002)$ & $(0.002)$ & $(0.002)$ \\
\hline \multirow[t]{2}{*}{ Temperature(T) } & $0.480 * * *$ & $0.013 * * *$ & $0.013 * * *$ & $0.013 * * *$ & $0.007^{*}$ & $0.006^{*}$ & $0.006^{*}$ \\
\hline & $(0.125)$ & $(0.003)$ & $(0.003)$ & $(0.003)$ & $(0.004)$ & $(0.003)$ & $(0.003)$ \\
\hline \multirow[t]{2}{*}{ No. rainy days $(\mathrm{R})$} & -0.001 & 0.000 & 0.001 & 0.000 & -0.003 & -0.001 & -0.003 \\
\hline & $(0.007)$ & $(0.003)$ & $(0.003)$ & $(0.003)$ & $(0.003)$ & $(0.003)$ & $(0.003)$ \\
\hline \multirow[t]{2}{*}{ PSI } & -0.002 & -0.001 & -0.001 & -0.001 & $0.005^{* * *}$ & $0.005 * * *$ & $0.005 * * *$ \\
\hline & $(0.112)$ & $(0.005)$ & $(0.005)$ & $(0.005)$ & $(0.001)$ & $(0.001)$ & $(0.001)$ \\
\hline \multirow[t]{2}{*}{$\mathrm{HIP}^{*} \mathrm{~T}$} & & 0.001 & & & 0.001 & & \\
\hline & & $(0.001)$ & & & $(0.003)$ & & \\
\hline \multirow[t]{2}{*}{ HIP*Completed*T } & & -0.001 & & & $-0.006^{* *}$ & & \\
\hline & & $(0.001)$ & & & $(0.003)$ & & \\
\hline \multirow[t]{2}{*}{$\mathrm{HIP}^{*} \mathrm{R}$} & & & $-0.002 *$ & & & $-0.009 * * *$ & \\
\hline & & & $(0.001)$ & & & $(0.002)$ & \\
\hline \multirow[t]{2}{*}{ HIP*Completed*R } & & & 0.001 & & & 0.005 & \\
\hline & & & $(0.001)$ & & & $(0.003)$ & \\
\hline \multirow[t]{2}{*}{ HIP*PSI } & & & & $0.001 *$ & & & 0.002 \\
\hline & & & & $(0.001)$ & & & $(0.002)$ \\
\hline \multirow[t]{2}{*}{ HIP*Completed*PSI } & & & & -0.002 & & & $-0.011 * * *$ \\
\hline & & & & $(0.001)$ & & & $(0.003)$ \\
\hline Group time trend & & Yes & Yes & Yes & Yes & Yes & Yes \\
\hline Account FE & & Yes & Yes & Yes & Yes & Yes & Yes \\
\hline Year-month FE & & Yes & Yes & Yes & Yes & Yes & Yes \\
\hline $\mathrm{N}$ & & 98291320 & 98291320 & 98291320 & 98291320 & 98291320 & 98291320 \\
\hline $\mathrm{R}^{2}$ & & 0.740 & 0.740 & 0.740 & 0.740 & 0.740 & 0.740 \\
\hline
\end{tabular}

Note: This table presents the interaction effect of HIP and temperature, rainfall, and air pollution on water consumption. The dependent variable is log of monthly water consumption. HIP is an indicator variable that takes the value of 1 for the treatment group; Completed is an indicator variable that takes the value of 1 for time periods post HIP completion. Column (1) shows the baseline estimates using log of mean temperature, $\log$ of number of rainy days and $\log$ of PSI as control variables. Columns (2) to (4) use standardized monthly mean temperature, number of rainy days and monthly mean PSI; while columns (5) to (7) use indicator variables that takes the value of 1 when the mean temperature and number of rainy days exceed 90th percentile and when PSI falls in the unhealthy category. All models include weather and pollution controls, group specific linear time trend, account fixed effects and year-month fixed effects. The standard errors are two-way clustered by block and year-month. ${ }^{*} \mathrm{p}<0.1,{ }^{* *} \mathrm{p}<0.05, * * * \mathrm{p}<0.01$. Standard error in parentheses. 


\section{Figures}

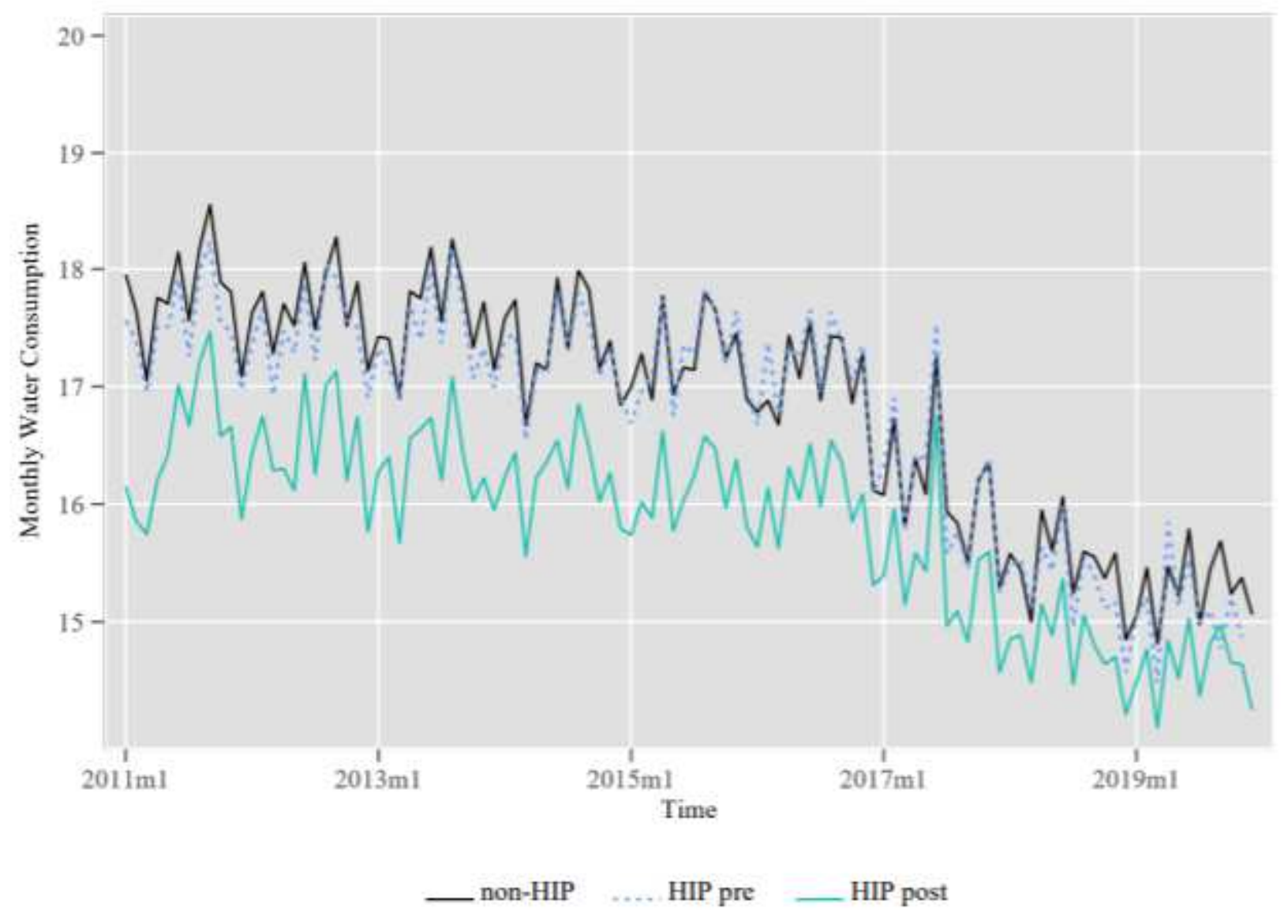

Figure 1

Trend of monthly water consumption. Note: The figure shows the trend in monthly mean water consumption (in cubic meter) for non-HIP flats, HIP flats before HIP completion, HIP flats after HIP completion over time. 


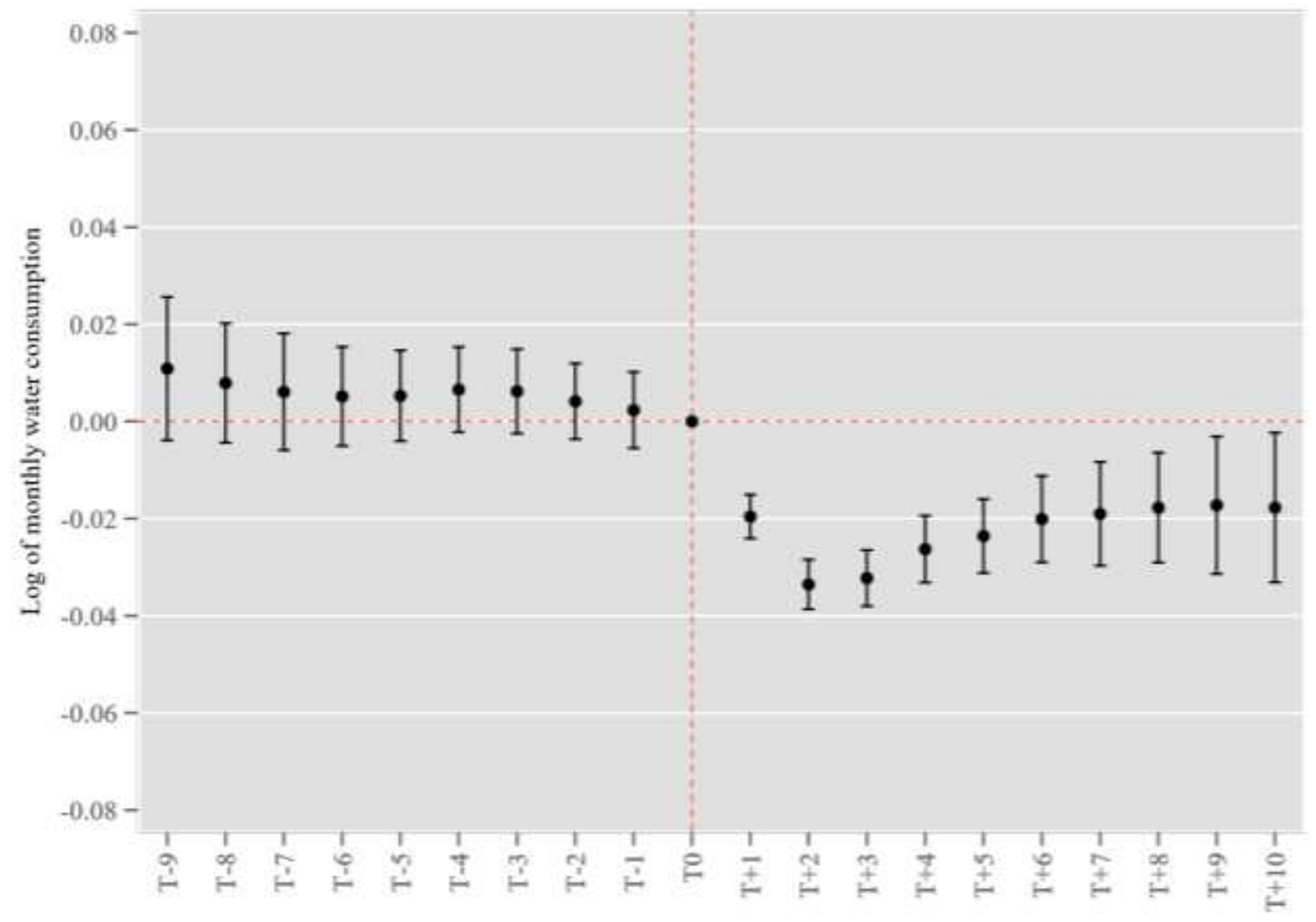

Figure 2

Evolutionary effect of HIP on water consumption. Note: The figure shows the coefficients and corresponding $95 \%$ confidence intervals for the difference in water consumption between flats that completed and did not complete HIP each year before and after HIP completion by estimating equation (3).

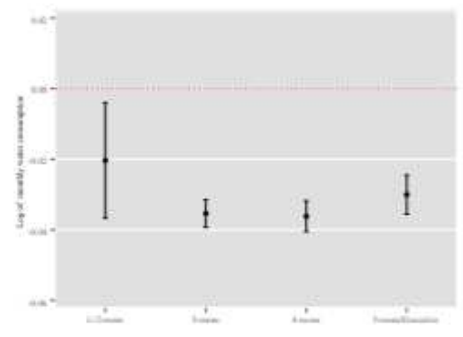

(a) By flat type

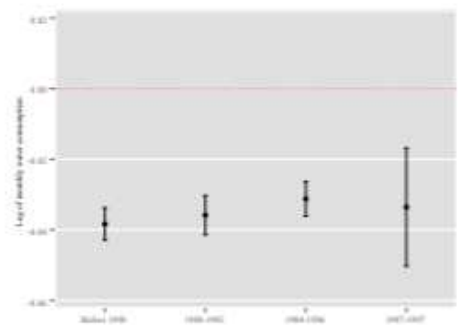

(b) By year of construction

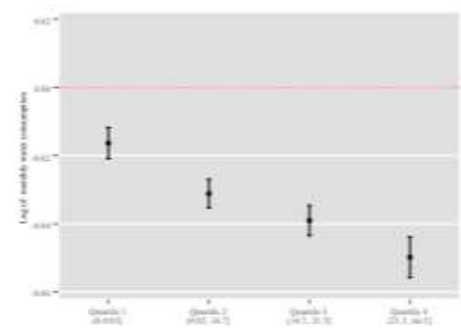

(c) By water consumption quartile

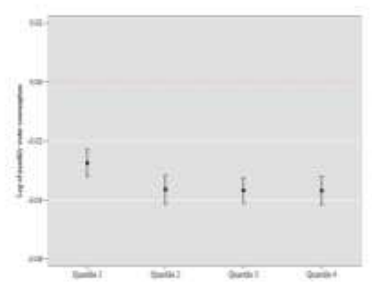

(d) By family size

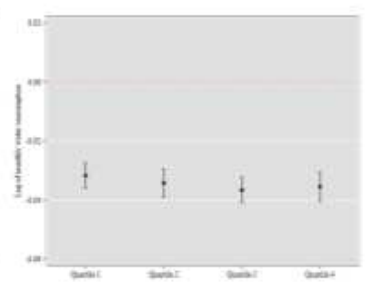

(e) By $\%$ of male

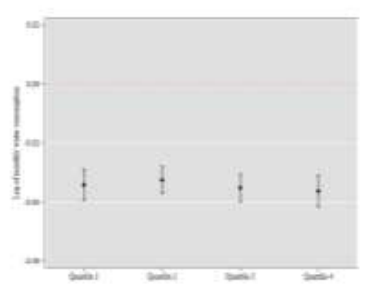

(f) $\mathrm{By} \%$ of Chinese

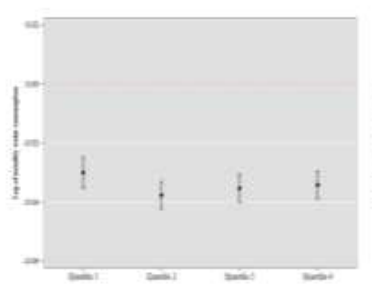

(g) By \% of elderly

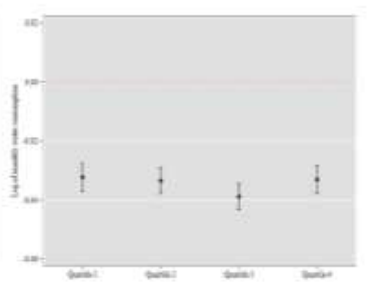

(h) By $\%$ of young family 


\section{Figure 3}

Heterogeneous effect by housing characteristics, water demand and block-level demographics. Note: The figures show the coefficients and corresponding 95\% confidence intervals for the effect of HIP on monthly water consumption for each subgroup by estimating equation (4). Sub-figures (a), (b) and (c) show the effects by flat type, year of construction, and water consumption quartile, respectively. Subfigures (d) to (h) present the heterogeneous effects by quartiles of family size, percentage of male, percentage of Chinese, percentage of elderly and percentage of young family.

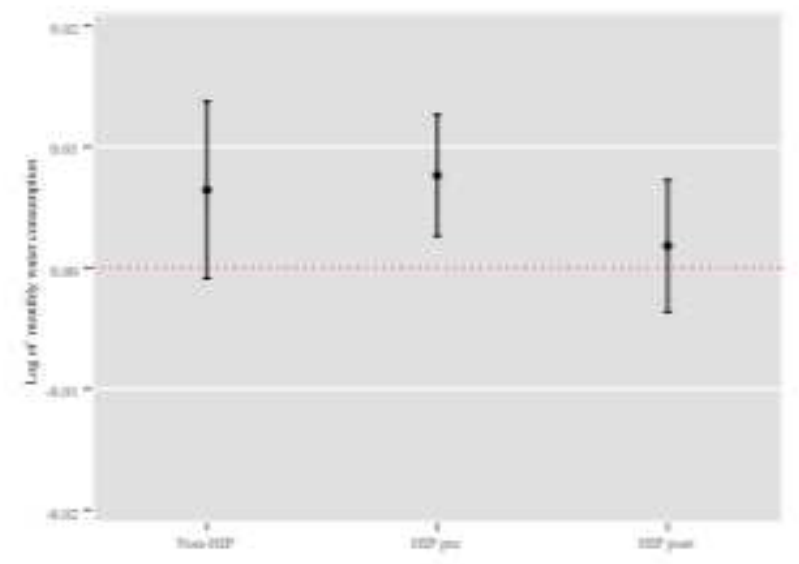

(a) Temperature

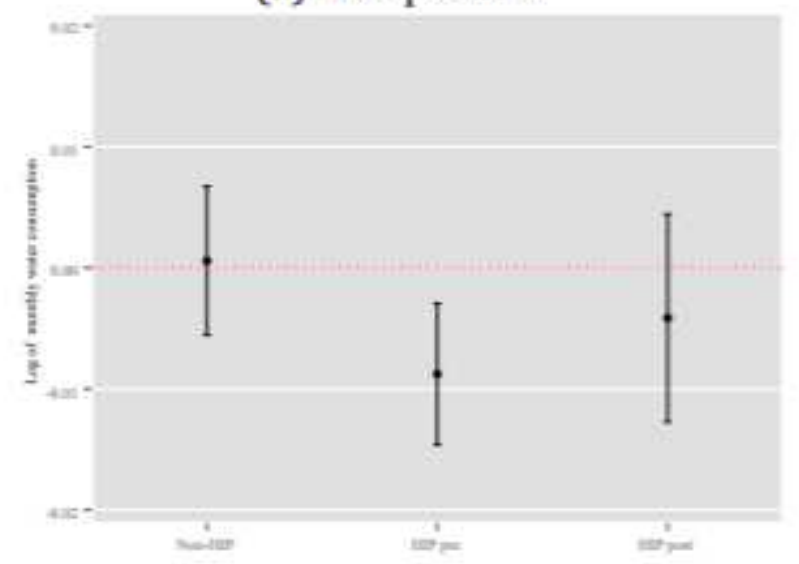

(b) Number of rainy days

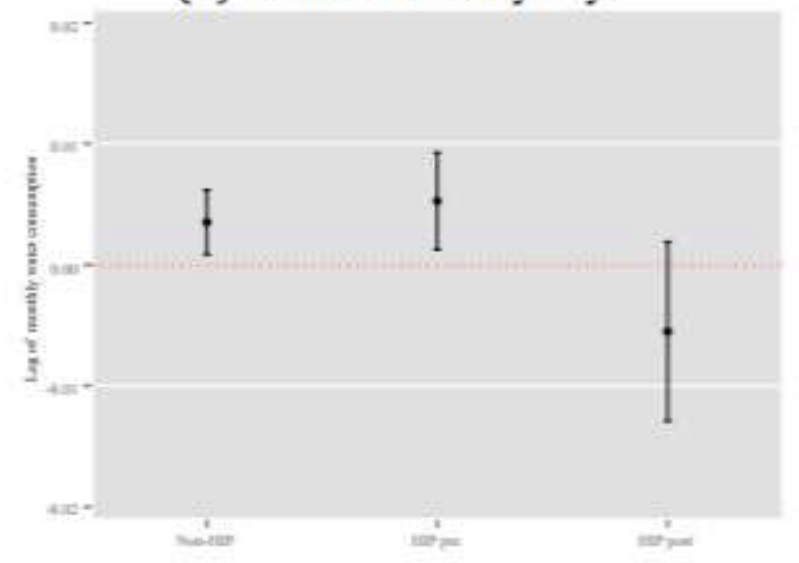

(c) PSI 


\section{Figure 4}

Effect of extreme environmental conditions on HIP vs non-HIP flats. Note: The figures show the coefficients and corresponding $95 \%$ confidence intervals for the effect of high temperature, excessive number of rainy days and high PSI on non-HIP flats $(\beta 1)$, HIP flats before $(\beta 1+\beta 2)$ and after $(\beta 1+\beta 2+$ B3) project completion, by estimating equation (5). To be more specific, the coefficients in Panels (a), (b) and (c) correspond to Table A.2.3 column (5) row 2, row $2+5$, and row $2+5+6$; column (6) row 3, row $3+7$, and row $3+7+8$; and column (7) row 4 , row $4+9$, and row $4+9+10$, respectively. 